\title{
The Utility of 2,2'-Bipyrimidine in Lanthanide Chemistry: From Materials Synthesis to Structural and Physical Properties
}

\author{
Gaël Zucchi \\ Ecole polytechnique, LPICM, CNRS UMR 7647, 91128 Palaiseau, France \\ Correspondence should be addressed to Gaël Zucchi, gael.zucchi@polytechnique.edu
}

Received 2 January 2011; Accepted 1 March 2011

Academic Editor: W. T. Wong

Copyright ( 2011 Gaël Zucchi. This is an open access article distributed under the Creative Commons Attribution License, which permits unrestricted use, distribution, and reproduction in any medium, provided the original work is properly cited.

This paper reviews the recent investigations undertaken on the use of 2,2' -bipyrimidine (bpm) as a ligand for designing molecular complexes as well as polymeric lanthanide materials. A special emphasis is put on the ability of this polydentate neutral ligand to yield compounds of various dimensionalities, to act as a connector between these large ions, and influence their emissive and magnetic properties. This ligand can adopt a terminal or a bridging coordination mode with lanthanide ions, thus generating a wealth of frameworks of various topologies with the $4 f$ elements. The main focus of this review is to show the originality brought by bpm in lanthanide structural chemistry and solid-state photophysics and magnetism.

\section{Introduction}

Lanthanide ions and their complexes with organic ligands have generated a continuously growing interest over the last decades. These elements show typical electronic properties that potentially give great advantages to the complexes they form with organic ligands. In the trivalent state, they are hard Lewis acids that have interesting applications in catalysis in the fields of polymer synthesis [1-7], organic chemistry [8-17], and bioinorganic chemistry [18-26]. Some of them possess a high number of unpaired electrons making them highly paramagnetic (the effective magnetic moment is up to $10.65 \mu_{\mathrm{B}}$ for $\mathrm{Dy}^{3+}$ ) [27] and of special interest for applications related to magnetic properties. In particular, they are widely studied for magnetic resonance imaging applications [2832], and their paramagnetism is used for obtaining NMR shift reagents that help the elucidation of solution structures of complex molecules such as proteins $[33,34]$, and chiral coordination complexes are useful for the determination of enantiomers [35-38]. Also, the trivalent lanthanide ions are subject of an excited research in molecular magnetism, especially since the discovery that a ferromagnetic interaction between $\mathrm{Cu}^{2+}$ and $\mathrm{Gd}^{3+}$ could occur [39]. However, the difficulty to find efficient synthetic strategies for obtaining such mixed $3 d-4 f$ compounds has been an impediment to the progress of this research area, and most of the studies were restricted to $\mathrm{Cu} / \mathrm{Gd}$ systems [40]. Among the series, $\mathrm{Gd}^{3+}$ was first investigated because its ground state is orbitally nondegenerate and well separated from the excited states, giving simple single ion magnetic properties. In the last years, studies have been extended to other paramagnetic trivalent lanthanide ions, and a special interest has been devoted to their use in single molecule magnets [41-46].

Luminescence is another field of thorough investigations. Trivalent lanthanide ions show intraconfigurational transitions which result in a rearrangement of the electrons within the $4 f$ subshell. A direct consequence is the atomlike character of their electronic spectra; that is, absorption and emission spectra show very thin lines with full-widths at half height typically of a few nanometers, giving rise to extremely pure colors of emission. A drawback of importance is the intensity of the lanthanide electronic spectra that are relatively low as the transitions are parity forbidden. In particular, the trivalent lanthanide ions show very low absorption coefficients in the $1^{-2}-10 \mathrm{~L} \cdot \mathrm{mol}^{-1} \cdot \mathrm{cm}^{-1}$ range, and powerful sources of excitation are needed to obtain emission of the metal ion after direct excitation within the excited states of the latter. To overcome this problem that could seriously hinder the development of the $4 f$ elements in organic and hybrid emissive materials, the antenna effect has appeared as a panacea. This is a three-step process that consists in efficient absorption of light by chromophores, 


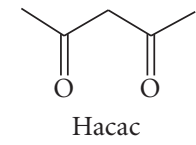

acetylacetone<smiles>[B]C(=O)CC(=O)C(F)(F)F</smiles>

hexafluoroacetylacetone

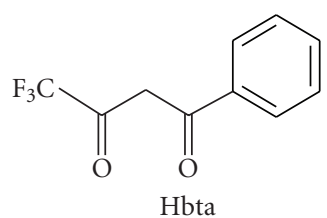

4,4,4-trifluoro-1-phenyl-1,3-butanedione<smiles>O=C(CC(=O)c1ccccc1)c1ccccc1</smiles>

Hdbm dibenzoylmethane<smiles>O=C(Br)CC(=O)c1cccs1</smiles>

2-thenoyltrifluoroacetone<smiles>O=C(CC(=O)C(F)(F)F)c1ccco1</smiles>

4,4,4-trifluoro-1-(2-furyl)-1,3-butanedione<smiles>CCCCCCCCC(=O)c1ccc2ccccc2c1</smiles>

4,4,4-trifluoro-1-(2-naphthyl)-1,3-butanedione

(6,6,7,7,8,8,8-heptafluoro-2,2-dimethyl-3,5-octanedione)

FIGURE 1: Structures and names of the commercial $\beta$-diketonates commonly used as ligands for the lanthanides.

transfer of a part of this light to the lanthanide ion which results in emission of the excited metal ion. The antenna effect has been well documented and the reader will find more precisions in some recent didactic review articles [47-49]. Another consequence to the special nature of the lanthanide luminescence is the long lifetimes of the emissive excited states that range from the $\mu$ s to the ms. Especially, $\mathrm{Eu}^{3+}$ and $\mathrm{Tb}^{3+}$ show lifetimes that frequently reach values in the ms order. This enables applications in the field of bioinorganic chemistry. In particular, lanthanide complexes have been developed in the so-called fluoroimmunoassays which consist in determining the concentration of an analyte such as antigens, hormones, or steroids for instance by using time-resolved spectroscopy $[50,51]$. Sensors based on the interaction between a luminescent lanthanide ion, and an analyte have also been developed [52-57].

Among organic ligands that serve as efficient antennae, the combination of $\beta$-diketonates and aromatic polypyridines has been frequently used with luminescent lanthanides $[58,59]$. $\beta$-diketonates are bidentate monoanionic ligands and some of them efficiently transfer energy to the lanthanide ions. The commercial $\beta$-diketonates that have been the most widely used with the lanthanide ions and their abbreviated names are reported on Figure 1. Lewis bases such as 2,2'-bipyridine or 1,10-phenanthroline (or their derivatives) are bidentate neutral ligands that strongly coordinate the trivalent lanthanide ions. The concomitant use of these two families of ligands leads to mononuclear neutral complexes of formulae $\left[\operatorname{Ln}(\beta)_{3}(\mathrm{~L})\right](\beta=\beta$-diketonate, $\mathrm{L}=2,2^{\prime}$-bipyridine (bipy) or 1,10-phenanthroline (Phen) or one of their derivatives) with increased stability and luminescent properties. In addition, these complexes (and espe- cially those made with $\beta$-diketonates featuring fluorine atoms [60]) show good volatility, a property of paramount importance for their processing by thermal evaporation. This combination of ligands sets results in heteroleptic complexes among which the best luminescent molecular materials have been obtained. For instance, the most luminescent molecular europium complex known is $\left[\mathrm{Eu}(\mathrm{tta})_{3}(\mathrm{dbso})\right]$ $(\mathrm{dbso}=$ dibenzoyl sulfoxide $)$ with a solid-state quantum yield as high as $85 \%$ [61].

It is only recently that chemists have started to investigate the ability of 2,2'-bipyrimidine to form complexes with the lanthanide ions. Luminescence studies have been performed on mixed d-f complexes [62-66], monometallic [67-69] and homo-bi- and polymetallic complexes [67, 70-80]. In particular, bpm was shown to connect a transition metal and a lanthanide ion, allowing sensitization of the lanthanide luminescence by the transition metal $[62,81]$. Also, 2,2'bipyrimidine was shown to allow an electronic connection between two lanthanide ions as revealed by magnestism investigations. It has been reported that antiferromagnetic interactions between two $4 f$ metal ions took place through bpm linkage $[82,83]$, and one report has shown that a weak ferromagnetic interaction occurred between two $\mathrm{Eu}$ (II) ions connected by bpm [84]. Most of these photophysical, and magnetism studies are closely related to the structural properties of the compounds.

This review aims at emphasizing the importance of the ligands sets used in the chemistry of lanthanides with $2,2^{\prime}$ bipyrimidine in the design of molecular compounds and coordination polymers of various dimensionalities. In a first section, an overview of the two coordination modes of bpm will be discussed based on the X-ray crystal structures 
of the complexes reported in the literature. The second section will be devoted to the relationship between structural and physical properties of the complexes, with respect to photophysical, electroluminescent and magnetic properties.

\section{Discussion}

\subsection{Structural Properties}

\subsubsection{2,2'-Bipyrimidine as a Bridging Ligand: Bimetallic Complexes and Coordination Polymers}

Heteroleptic Complexes Comprising bpm and $\beta$-diketonates. $2,2^{\prime}$-bipyrimidine has been shown to give rise to an interesting variety of structures when coordinated to lanthanide ions. Compounds from 0D molecular complexes to $3 \mathrm{D}$ hybrid organic-inorganic frameworks, through $1 \mathrm{D}$ bimetallic complexes and 1D coordination polymers were obtained and structurally described. In particular, when combined with $\beta$-diketonates, molecular complexes and 1D hybrid organic-inorganic frameworks were obtained and structurally described. These architectures are described hereafter.

The synthesis of lanthanide complexes with bpm and $\beta$ diketonates is relatively straightforward. Usually, the reaction is conducted by mixing the deprotonated $\beta$-diketones, bpm and the chloride or nitrate salt of the lanthanide ion. The complex readily precipitates from the reaction mixture. In most cases, homodinuclear complexes of general formula $\left[\left\{\operatorname{Ln}(\beta)_{3}(\mathrm{X})_{n}(\text { solv })_{m}\right\}_{2}(\mu\right.$-bpm $\left.)\right](\operatorname{Ln}=\mathrm{Nd}, \mathrm{Eu}, \mathrm{Gd}, \mathrm{Tb}, \mathrm{Ho}$, Er, $\left.\mathrm{Yb}, \mathrm{Lu} ; \mathrm{X}=\mathrm{NO}_{3}{ }^{-}, \mathrm{Cl}^{-} ; n=0,3 ; m=0,1\right)$ were obtained after recrystallization $[67,70-78]$. The structure of the complex $\left[\left\{\mathrm{Nd}(\mathrm{dbm})_{3}(\mathrm{THF})\right\}_{2}(\mu\right.$-bpm) $]$ is shown at the top of Figure 2 as a representative example. These bimetallic compounds show that bpm can coordinate large metal ions from both sides. Polymetallic complexes of higher nuclearity were also reported with the $\mathrm{Nd}^{3+}$ ion (Figure 2, bottom) [67]. In these complexes, no sizeable distortion of the plan defined by the two pyrimidine rings was observed. Another coordination polymer was reported with the $\mathrm{Nd}^{3+}$ ion, namely, $\left[\left\{\mathrm{Nd}(\mathrm{hfa})_{3}\right\}_{2}(\mu \text {-bpm })\right]_{\infty}[79]$, and two other ones were reported with the smaller $\mathrm{Eu}^{3+}[80]$, and $\mathrm{Gd}^{3+}$ ions [79]. This structural feature is of importance in view of the use of bpm as a connecting ligand for the design of extended structures. The bond lengths between the nitrogen atoms of the bpm ligand and the metal ion are slightly higher than those reported for compounds with other Lewis bases such as 1,10-phenanthroline. For instance, the Eu-N average distance is $2.687(9) \AA$ in [ $\left\{\mathrm{Eu}(\mathrm{tta})_{3}\right\}_{2}(\mu$-bpm)] [72], while it is only $2.594(11) \AA$ in $\left[\mathrm{Eu}(\mathrm{tta})_{3}(\mathrm{Phen})\right]$ [85]. This difference is mostly related to the more pronounced basic character of the 1,10-phenanthroline compared to that of 2,2'-bipyrimidine.

By using strictly identical experimental conditions, it was shown that the $\beta$-diketonates used could induce structural changes in the final product. Indeed, the reaction conducted in absolute ethanol between the $\beta$-diketonates, an aqueous solution of sodium hydroxide as the base and neodymium chloride lead to the isolation of compounds of different
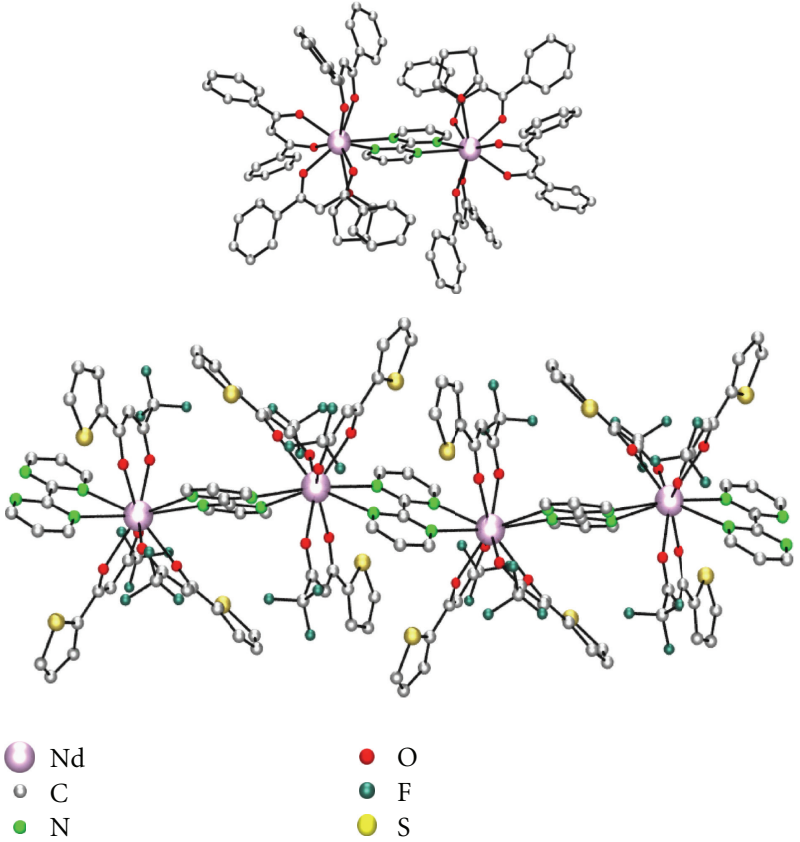

FIGURE 2: Structure of the bimetallic complex $\left[\left\{\mathrm{Nd}(\mathrm{dbm})_{3}(\mathrm{THF})\right\}_{2}\right.$ $(\mu$-bpm) $]($ top $)$ and of the coordination polymer $\left[\left\{\mathrm{Nd}(\mathrm{tta})_{3}\right\}_{2}(\mu-\right.$ bpm)] (bottom).

formula, depending on the $\beta$-diketonate used. A bimetallic complex of formula $\left[\left\{\mathrm{Nd}(\mathrm{bta})_{3}(\mathrm{MeOH})\right\}_{2}(\mu\right.$-bpm $\left.)\right] \cdot \mathrm{bpm}$ $(3 \cdot \mathrm{bpm})$ was obtained after recrystallization from methanol, while the coordination polymer $\left[\left\{\mathrm{Nd}(\mathrm{tta})_{3}\right\}_{2}(\mu \text {-bpm })\right]_{\infty}$ was obtained in exactly the same experimental conditions [67]. Another similar example can be found in the literature. Two papers published by the same group have also shown that complexes of different dimensionality could be obtained depending on the $\beta$-diketonate used. Two bimetallic complexes of formula $\left[\left\{\mathrm{Eu}(\beta)_{3}\right\}_{2}(\mu\right.$-bpm) $](\beta=\mathrm{tfa}$, tta) were obtained [73], while the one-dimensional coordination polymer $\left[\left\{\mathrm{Eu}(\mathrm{hfa})_{3}\right\}_{2}(\mu \text {-bpm })\right]_{\infty}$ has been isolated with identical experimental conditions [80]. Comparison of the products formed along the lanthanide series with the same set of ligands suffers from the scarcity of the examples that can be found in the literature. In consequence, no real influence of the metal ion can be brought out on the structure of the final compounds. Going from $\mathrm{Nd}^{3+}$ to $\mathrm{Lu}^{3+}$, bimetallic complexes of formula $\left[\left\{\operatorname{Ln}(\text { fod })_{3}\right\}_{2}(\mu\right.$-bpm $\left.)\right](\mathrm{Ln}=\mathrm{Nd}, \mathrm{Eu}$, $\mathrm{Tb}$, $\mathrm{Ho}$ and $\mathrm{Lu})$ were obtained [77, 78]. However, the system (Ln, hfa, bpm) afforded one-dimensional coordination polymers of formula $\left[\left\{\operatorname{Ln}(\mathrm{hfa})_{3}\right\}_{2}(\mu \text {-bpm })\right]_{\infty}$ with the $\mathrm{Nd}^{3+}, \mathrm{Eu}^{3+}$ and $\mathrm{Gd}^{3+}$ ions, while the monometallic complex $\left[\mathrm{Tb}(\mathrm{hfa})_{3}(\mathrm{bpm})\left(\mathrm{H}_{2} \mathrm{O}\right)\right]$ was isolated with the $\mathrm{Tb}^{3+}$ ion. A caveat should be put on this latter observation as this $\mathrm{Tb}$ complex could originate from the presence of the strongly coordinating water ligand, and, as it will be described below, a strongly coordinating solvent like water can induce structural changes in compounds formed between Ln ions and $\mathrm{bpm}$. At that point, further comparison between structures of complexes reported by different authors appears to be 


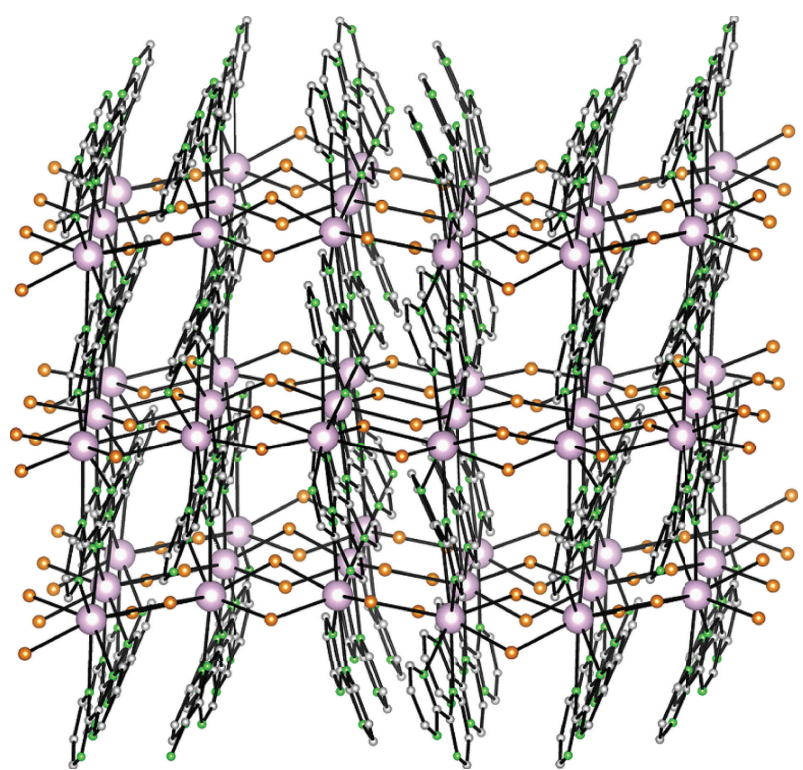

FIGURE 3: Structure of the 3D coordination polymer $\left[\mathrm{EuCl}_{2}(\mathrm{bpm})\right.$ $\left.(\mathrm{MeOH})_{0.5}\right]_{\infty}$ (see Figure 2 for legend, $\mathrm{Cl}^{-}$: orange).

quite tricky as the experimental conditions used by each group are not identical to each other.

Some interesting investigations on the stability of the $\left[\left\{\operatorname{Ln}(\text { fod })_{3}\right\}_{2}(\mu-\mathrm{bpm})\right](\mathrm{Ln}=\mathrm{Eu}, \mathrm{Tb}, \mathrm{Ho})$ complexes were reported $[77,78]$. It was shown that these dinuclear complexes were stable at temperature as high as $200^{\circ} \mathrm{C}$ and melt at $215^{\circ} \mathrm{C}$. In addition, their melting point is higher than that of their mononuclear analogues made with 1,10 phenanthroline and 2,2'-bipyridine. No change in these parameters seems to occur when going from one metal ion to another one, as earlier shown with the $\left[\left\{\operatorname{Ln}(n t a)_{3}\right\}_{2}(\mu\right.$ bpm)] $(\mathrm{Ln}=\mathrm{Eu}, \mathrm{Gd})$ system [70]. These data are important in view of the use of such complexes as molecular materials processed by thermal evaporation.

The systems comprising $\beta$-diketonates described above have been the most investigated. However, a few structures of complexes comprising lanthanide ions and bpm as a bridging ligand without $\beta$-diketonates have been reported. They are described hereafter.

Complexes without $\beta$-diketonates. In addition to the $1 \mathrm{D}$ coordination polymers described above, some metal organic frameworks in which bpm acts as a connector between the lanthanide ions were described. The $3 \mathrm{D}$ coordination polymer $\left[\{\mathrm{Eu}\}_{2}(\mu-\mathrm{Cl})_{2}(\mu \text {-bpm }) \cdot 0.5 \mathrm{MeOH}\right]_{\infty}$ was obtained by reacting $\mathrm{EuCl}_{2}$ and bpm in anhydrous anaerobic conditions [84]. In this compound, $\left\{\mathrm{EuCl}_{2}\right\}_{n}$ polymeric chains are formed via connection of the $\mathrm{Eu}^{2+}$ centers through the chloride ions, and the metal ions are further connected by the bridging bpm ligands so as to form a three-dimensional framework (Figure 3). This is the only 3D framework comprising bpm known with the lanthanide ions.

Only two systems comprising ligands other than $\beta$-diketonates and yielding bimetallic complexes structurally characterized were recently reported. These compounds are
$\left[\left\{\mathrm{Nd}(\mathrm{L})_{3}\right\}_{2}(\mu\right.$-bpm) $] \quad(\mathrm{L}=$ dimethyl-N-trichloracetylamidophosphato) [69] and $\left[\left\{\mathrm{Eu}\left(\mathrm{NO}_{3}\right)_{3}(\mathrm{bpm})\right\}_{2}(\mu\right.$-bpm) $) \cdot \mathrm{H}_{2} \mathrm{O}$ [74]. The $\left[\left\{\operatorname{Ln}(\mathrm{X})_{3}\right\}_{2}(\mu\right.$-bpm $\left.)\right]$ complexes were synthesized from reaction in isopropanol between the sodium salt of the $\mathrm{CAPh}$ ligand and the nitrate salts of the lanthanide ions, and crystals suitable for X-ray diffraction of the $\mathrm{Nd}$ complex were grown from the reactant medium. The structure is formed of dimers made of two metal ions bridged by bpm, and each ion is coordinated by three monoanionic carbacycloamidophosphates (CAPh) that are also strongly coordinating for the lanthanides. The bimetallic complexes formed with the $\mathrm{Eu}^{3+}$ and $\mathrm{Gd}^{3+}$ ions were described and analytically characterized, and the magnetic properties of the three complexes were investigated (see Section 2).

The existence of complex $\left[\left\{\mathrm{Eu}\left(\mathrm{NO}_{3}\right)_{3}(\mathrm{bpm})\right\}\right]_{2}(\mu-$ bpm)] $\cdot \mathrm{H}_{2} \mathrm{O}$ shows that bpm can adopt two coordination modes with the lanthanide ions, at least the $\mathrm{Eu}^{3+}$ ion. Indeed, in this complex, one bpm unit bridges two $\mathrm{Eu}^{3+}$ ions, while each metal ion also bears another bpm molecule that only coordinates through two nitrogen atoms and three bidentate nitrates. This is an example of the terminal coordination mode that can adopt bpm with lanthanide ions and which is described hereafter.

2.1.2. Monometallic Complexes: bpm as a Terminal Ligand. One complete structural study reporting monometallic complexes along the series in which bpm acts as a terminal ligand was published by the author and colleagues [68]. It was shown that the reaction between bpm and the nitrate salts of the lanthanides in dry THF yielded a series of isomorphous complexes of formula $\left[\mathrm{Ln}\left(\mathrm{NO}_{3}\right)_{3}(\mathrm{bpm})_{2}\right]$ $(\mathrm{Ln}=\mathrm{Nd}, \mathrm{Sm}, \mathrm{Eu}, \mathrm{Gd}, \mathrm{Tb}, \mathrm{Dy}, \mathrm{Er}, \mathrm{Tm}, \mathrm{Yb})$. A view of the representative structure of the series is shown on Figure 4(a). The structure resembles that of the $2,2^{\prime}$ bipyridine (bipy) analogues $\left.\left[\mathrm{Ln}\left(\mathrm{NO}_{3}\right)_{3} \text { (bipy }\right)_{2}\right][86,87]$. However, here again, the average $\mathrm{Ln}-\mathrm{N}$ distances appear to be greater, by $0.03-0.05 \AA$, than the corresponding distances in the analogues comprising the more basic bipy ligand. In this family of complexes, the usual linear relationship between the $\mathrm{Ln}-\mathrm{O}$ and $\mathrm{Ln}-\mathrm{N}$ distances and the radii of the $\mathrm{Ln}^{3+}$ ions is respected, with $r^{2}$ coefficients larger than 0.99 . The structures of the products obtained from the same reaction conducted with the larger $\mathrm{Ce}^{3+}$, $\mathrm{Nd}^{3+}$, and $\mathrm{Sm}^{3+}$ ions were found to be solvent dependent. Complexes $\left[\mathrm{Ln}\left(\mathrm{NO}_{3}\right)_{3}(\mathrm{bpm})_{2}\right] \cdot \mathrm{THF} \quad(\mathrm{Ln}=\mathrm{Nd}, \mathrm{Sm})$ and $\left[\mathrm{Ln}\left(\mathrm{NO}_{3}\right)_{3}(\mathrm{bpm})(\mathrm{MeOH})_{2}\right] \cdot \mathrm{MeOH}(\mathrm{Ln}=\mathrm{Ce}, \mathrm{Nd}, \mathrm{Sm})$ were obtained from recrystallization from THF and methanol, respectively. This feature is likely related to the fact that the bpm ligand is more tightly bound to the smaller lanthanide ions which are more Lewis acidic. A view of the structure of the complexes $\left[\mathrm{Ln}\left(\mathrm{NO}_{3}\right)_{3}(\mathrm{bpm})(\mathrm{MeOH})_{2}\right] \cdot \mathrm{MeOH}$ is shown on Figure 4(b). The fact that one or two bpm molecules can coordinate to the metal ion is of interest in view of designing frameworks of different topologies. These compounds are rare examples of lanthanide complexes with bpm as a terminal ligand, and with the recently reported $\left[\mathrm{Tb}(\mathrm{hfa})_{3}(\mathrm{bpm})\left(\mathrm{H}_{2} \mathrm{O}\right)\right][79]$ and $\left[\mathrm{Nd}(\mathrm{X})_{3}(\mathrm{bpm}]\left(\mathrm{X}=\mathrm{N}, \mathrm{N}^{\prime}-\right.\right.$ dipyrrolidine- $\mathrm{N}^{\prime \prime}$-trichloracetylphosphortriamido) [69] complexes, they are the only mononuclear lanthanide 


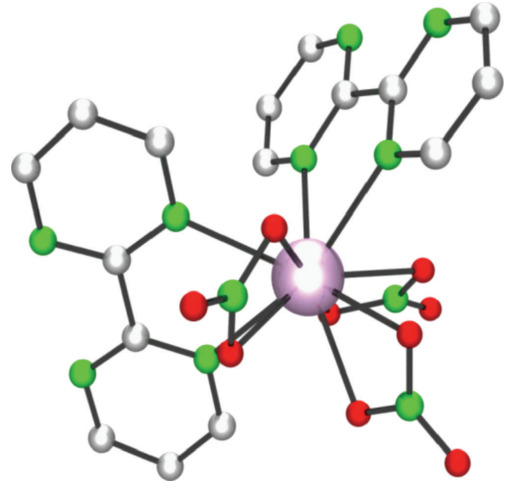

(a)

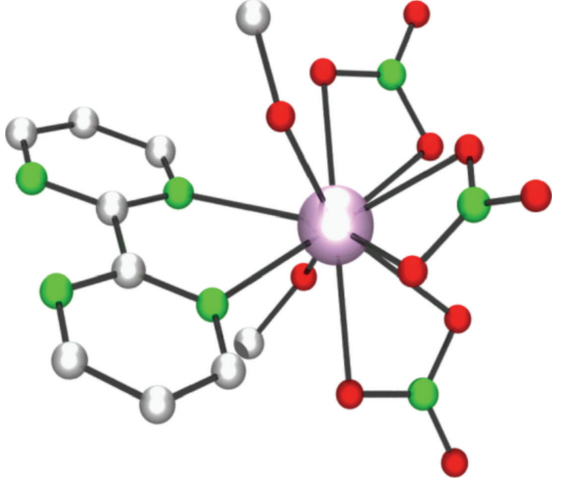

(b)

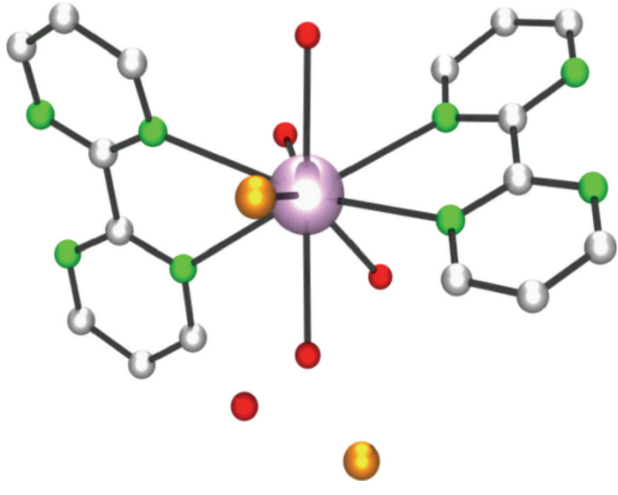

(c)

Figure 4: Representative structure of the (a) $\left[\mathrm{Ln}\left(\mathrm{NO}_{3}\right)_{3}(\mathrm{bpm})_{2}\right](\mathrm{Ln}=\mathrm{Nd}, \mathrm{Sm}, \mathrm{Eu}, \mathrm{Gd}, \mathrm{Tb}, \mathrm{Dy}, \mathrm{Er}, \mathrm{Tm}, \mathrm{Yb},)_{,}(\mathrm{b})\left[\mathrm{Ln}(\mathrm{NO})_{3}(\mathrm{bpm})\right.$ $\left.(\mathrm{MeOH})_{2}\right] \cdot \mathrm{MeOH}(\mathrm{Ln}=\mathrm{Ce}, \mathrm{Nd}, \mathrm{Sm})$, and $(\mathrm{c})\left[\mathrm{EuCl}(\mathrm{bpm})_{2}\left(\mathrm{H}_{2} \mathrm{O}\right)_{4}\right]^{+}[\mathrm{Cl}]^{-} \cdot \mathrm{H}_{2} \mathrm{O}$ monometallic complexes (see Figures 2 and 3 for legend).

compounds comprising bpm to have been crystallographically characterized.

These complexes have limited stability, especially in aerated solution. The presence of a stronger coordinating solvent such as water can be responsible of partial decomposition of the compounds and can lead to the formation of complexes with unpredictable structures. A few structures of hydrated complexes have been reported: the alreadymentioned terbium complex $\left[\mathrm{Tb}(\mathrm{hfa})_{3}(\mathrm{bpm})\left(\mathrm{H}_{2} \mathrm{O}\right)\right]$ [79], the cationic ytterbium complex $\left[\mathrm{Yb}\left(\mathrm{NO}_{3}\right)_{3}(\mathrm{bpm})\left(\mathrm{H}_{2} \mathrm{O}\right)_{3}\right]^{+}$ [68], and a more "exotic" compound that exists as a cation-anion pairs of formula $\left[\mathrm{Ce}\left(\mathrm{NO}_{3}\right)_{2}(\mathrm{bpm})\left(\mathrm{H}_{2} \mathrm{O}\right)_{4}\right]^{+}$ $\left[\mathrm{Ce}\left(\mathrm{NO}_{3}\right)_{4}(\mathrm{bpm})\left(\mathrm{H}_{2} \mathrm{O}\right)_{4}\right]^{-}[68]$. It has been shown that, when dissolved in water, the $3 \mathrm{D}$ coordination polymer $\left[\{\mathrm{Eu}\}_{2}(\mu-\mathrm{Cl})_{2}(\mu \text {-bpm }) \cdot 0.5 \mathrm{MeOH}\right]_{\infty}$ was broken, and the monometallic complex $\left[\mathrm{EuCl}(\mathrm{bpm})_{2}\left(\mathrm{H}_{2} \mathrm{O}\right)_{4}\right]^{+}[\mathrm{Cl}]^{-} \cdot \mathrm{H}_{2} \mathrm{O}$ (Figure 4(c)) was recrystallized from the aqueous solution.

However, lanthanide complexes with bpm were described to be relatively air stable in the solid state. Thus, investigations of their physical properties seemed to be the next step in view of their practical use.

\subsection{Photophysical, Electroluminescent, and \\ Magnetic Properties}

\subsubsection{Solid State Photophysical Properties}

Monometallic [ $\left.\mathrm{Ln}\left(\mathrm{NO}_{3}\right)_{3}(\mathrm{bpm})_{2}\right]$ Complexes. Most of the investigations of the photophysical properties of lanthanide complexes bearing bpm ligands were performed in solution on complexes formed with $\beta$-diketonates. However, the role of bpm as a possible sensitizer of the luminescence of the lanthanide ions was not taken into consideration. Only emission spectra recorded after excitation of the $\beta$ diketonates were reported. Below is described the role that bpm plays in the sensitization process of the luminescence of the trivalent lanthanide ions, with respect to interaction with the $\beta$-diketonates in the energy migration pathway and the direct excitation of the metal ions.

Depending on the metal ion, complexes are investigated as molecular materials with potential applications as solid

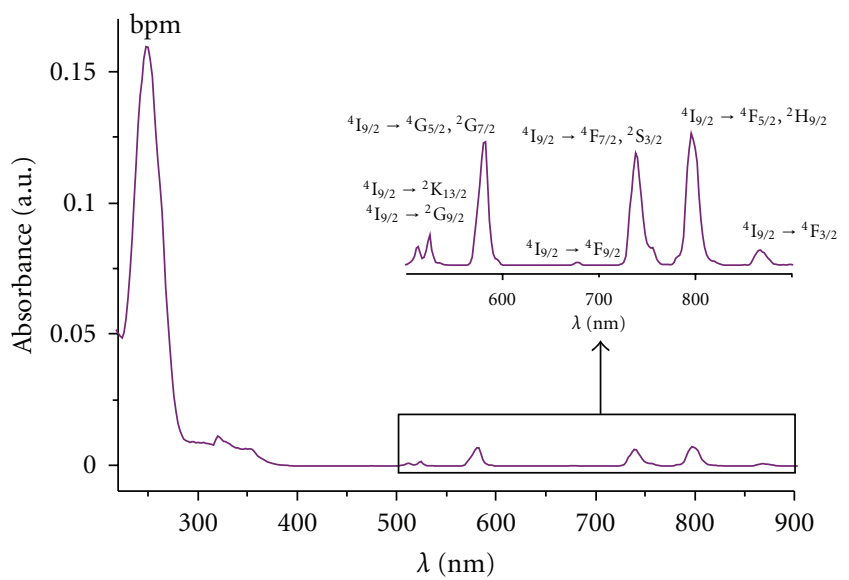

FIGURE 5: Solid-state absorption spectrum of $\left[\mathrm{Nd}\left(\mathrm{NO}_{3}\right)_{3}(\mathrm{bpm})_{2}\right]$ (5\% in $\mathrm{MgO})$.

state emitters in photonic or optoelectronic devices. Within these lines, it appeared desirable to study their photophysical properties in the solid state. Isolation of the monometallic complexes of general formula $\left[\mathrm{Ln}\left(\mathrm{NO}_{3}\right)_{3}(\mathrm{bpm})_{2}\right]$ with the visible and near infrared emissive lanthanide ions allowed us to evaluate the ability of bpm to act as an antenna for these ions. Indeed, bpm was the only sensitizer present in the molecules, the nitrates ions being nonactive as far as photophysical properties are concerned. The absorption spectrum of $\left[\mathrm{Nd}\left(\mathrm{NO}_{3}\right)_{3}(\mathrm{bpm})_{2}\right]$ is shown on Figure 5. In addition to the sharp and poorly intense absorption bands arising from the ${ }^{4} \mathrm{I}_{9 / 2}$ ground state of the $\mathrm{Nd}^{3+}$ ion, it shows a broad and intense absorption in the UV region with a maximum at $249 \mathrm{~nm}$. This band was described to be a $\pi-\pi^{*}$ or an $\mathrm{n}-\pi^{*}$ transition of the bpm. When excited within this broad band, the complexes showed the typical emission lines of the lanthanide ions. Furthermore, the excitation spectra of the complexes recorded when monitoring of the metal ion emission lines all showed a broad band attributed to $\pi$ $\pi^{*}$ and/or $\mathrm{n}-\pi^{*}$ transitions within the electronic states of 


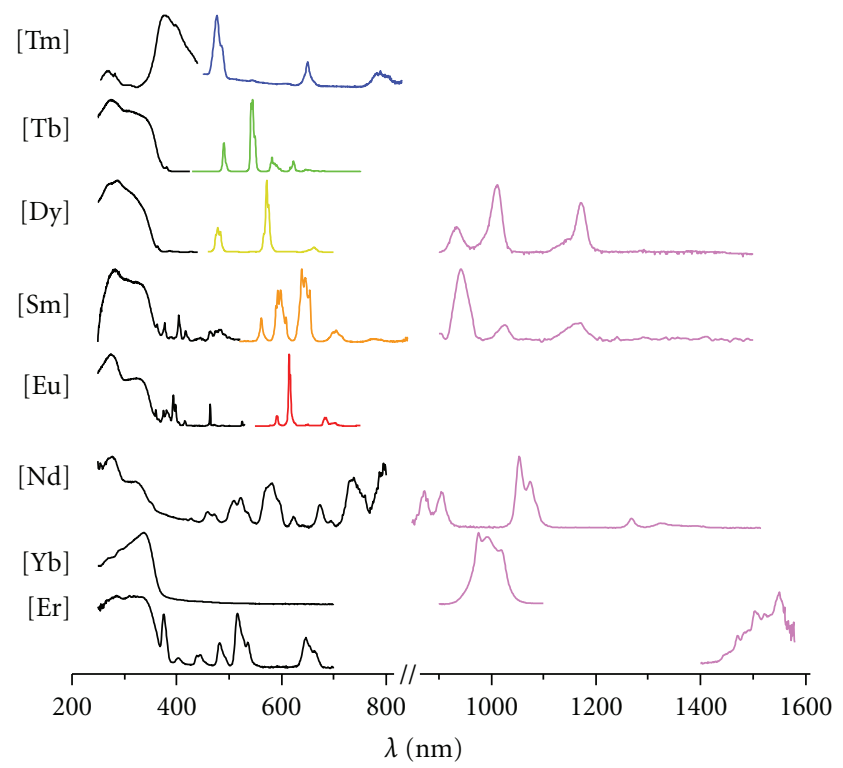

Figure 6: Excitation (black traces) and emission spectra (of the complexes $\left[\mathrm{Ln}\left(\mathrm{NO}_{3}\right)_{3}(\mathrm{bpm})_{2}\right] \mathrm{Ln}=\mathrm{Nd}, \mathrm{Sm}, \mathrm{Eu}, \mathrm{Tb}, \mathrm{Dy}, \mathrm{Er}, \mathrm{Tm}$, $\mathrm{Yb})$ in the solid state. Excitation spectra have been measured by monitoring the most intense band of the emission spectrum for each ion, and emission spectra have been obtained after excitation within the excited electronic states of bpm $\left(\lambda_{\mathrm{exc}}=330 \mathrm{~nm}\right)$.

the organic bpm ligand in addition to the typical narrow $f-f$ absorption bands of the $\mathrm{Ln}^{3+}$ ions (Figure 6). These spectra clearly indicate that an energy transfer occurred from the bpm to the metal ions, resulting in emission of the latter. Measurements of the overall quantum yields afforded very high values of 80.0 and $70.0 \%$ for the $\mathrm{Tb}^{3+}$ and $\mathrm{Eu}^{3+}$ complexes, respectively. An interesting value of $5.1 \%$ was measured for the Dy complex. The sensitization of the luminescence of the near-IR $\mathrm{Yb}^{3+}$ emitter by bpm was also found to be relatively efficient with a value of $0.8 \%$ for the overall quantum yield. As reported on Figure 6, emission of the $\mathrm{Tm}^{3+}, \mathrm{Nd}^{3+}$, and $\mathrm{Er}^{3+}$ ions was also observed after excitation within the excited states of the bpm, but the intensity was too low for measurements of the quantum yields. Also, a more rarely described phenomenon observed is the near-IR emission from the Sm(III) and Dy(III) ions. The three transitions ${ }^{4} \mathrm{G}_{5 / 2} \rightarrow{ }^{4} \mathrm{~F}_{5 / 2}(943 \mathrm{~nm}),{ }^{4} \mathrm{G}_{5 / 2} \rightarrow{ }^{4} \mathrm{~F}_{7 / 2}$ $(1024 \mathrm{~nm})$, and ${ }^{4} \mathrm{G}_{5 / 2} \rightarrow{ }^{4} \mathrm{~F}_{9 / 2}(1169 \mathrm{~nm})$ were observed for $\left[\mathrm{Sm}\left(\mathrm{NO}_{3}\right)_{3}(\mathrm{bpm})_{2}\right]$ and emission bands with maxima at $933\left({ }^{4} \mathrm{~F}_{9 / 2} \rightarrow{ }^{6} \mathrm{~F}_{7 / 2}\right), 1011\left({ }^{4} \mathrm{~F}_{9 / 2} \rightarrow{ }^{6} \mathrm{~F}_{5 / 2}\right)$ and $1172 \mathrm{~nm}$ $\left({ }^{4} \mathrm{~F}_{9 / 2} \rightarrow{ }^{6} \mathrm{~F}_{3 / 2}\right)$ were observed for $\left[\mathrm{Dy}\left(\mathrm{NO}_{3}\right)_{3}(\mathrm{bpm})_{2}\right]$. In addition to the emission of the metal ions, two broad emission lines attributed to the emission of the singlet and triplet excited states of the bpm, respectively, were observed on the emission spectra of the less luminescent $\mathrm{Tm}^{3+}, \mathrm{Nd}^{3+}$, and $\mathrm{Er}^{3+}$ complexes. The maximum intensity of the former was located around $230 \mathrm{~nm}$, while the maximum of the emission of the triplet state was comprised between 400 and $450 \mathrm{~nm}[67,68]$. These results show that bpm can sensitize the luminescence of the lanthanide ions from the visible to the near-IR region of the electromagnetic spectrum. The high values obtained for both the $\mathrm{Tb}$ and $\mathrm{Eu}$ complexes is an interesting result, as, usually, an efficient chromophore for the $\mathrm{Tb}^{3+}$ ion does not transfer efficiently energy to the $\mathrm{Eu}^{3+}$ ion for energy considerations.

Heteroleptic $\left[\mathrm{Nd}(\beta)_{3}(\mathrm{bpm})_{x}(\mathrm{solv})_{n}\right]$ Complexes. Photophysical investigations on the neodymium complexes comprising bpm and $\beta$-diketonates were also performed [67]. Emission spectra of these compounds conditioned as microcrystalline powders are reported on Figure 7. When excited at 260$270 \mathrm{~nm}$ (a range of wavelengths that mostly corresponds to a $\pi-\pi^{*}$ band of bpm) and $350 \mathrm{~nm}$ (within the $\beta$-diketonate $\pi-\pi^{*}$ bands), the complexes $\left[\left\{\mathrm{Nd}(\mathrm{dbm})_{3}(\mathrm{THF})\right\}_{2}(\mu\right.$-bpm $\left.)\right]$, $\left[\left\{\mathrm{Nd}(\mathrm{bta})_{3}(\mathrm{MeOH})\right\}_{2}(\mu\right.$-bpm $\left.)\right] \cdot \mathrm{bpm} \quad(3 \cdot \mathrm{bpm}), \quad\left[\mathrm{Nd}(\mathrm{tta})_{3}\right.$ $(\mathrm{bpm})]_{\infty}$, and $\left[\mathrm{Nd}(\mathrm{nta})_{3}(\mathrm{bpm})\right]_{x}$ showed, though weak, the characteristic narrow near-IR emission bands from the ${ }^{4} \mathrm{~F}_{3 / 2}$ excited state to the ${ }^{4} \mathrm{I}_{J}$ manifold. Complexes $\left[\left\{\mathrm{Nd}(\mathrm{bta})_{3}(\mathrm{MeOH})\right\}_{2}(\mu\right.$-bpm $\left.)\right] \cdot \mathrm{bpm}(3 \cdot \mathrm{bpm}),\left[\left\{\mathrm{Nd}(\mathrm{tta})_{3}\right\}_{2}\right.$ $(\mu$-bpm $)]_{\infty}$, and $\left[\mathrm{Nd}(\mathrm{nta})_{3}(\mathrm{bpm})\right]_{x}$ exhibited bpm phosphorescence between 370 and $580 \mathrm{~nm}$ with a similar envelope whatever the excitation wavelength used. This emission revealed that the triplet state of the bpm was populated when the $\beta$-diketonate ligands are excited and was the consequence of an energy transfer from the singlet state of the $\beta$-diketonates to the triplet state of bpm. The energetic diagrams that show the energy pathways in these $\mathrm{Nd}$ complexes are shown on Figure 8. It was observed that the emission spectrum of the complex formed with $\mathrm{dbm}$ as the $\beta$-diketonate showed emission from both bpm and the $\mathrm{dbm}$ ligands. This was explained as a lower efficiency of the energy transfer between the $\beta$-diketonates and the bpm with $\mathrm{dbm}$.

There are two reports in the literature dealing with the use of bimetallic complexes with the ( $\mathrm{Ln}, \beta$-diketonates, bpm) system as phosphorescent emitters in Organic Light Emitting Diodes (OLEDs). A first device with the following structure was described in 2006: ITO/PEDOT/PVK + PBD + $\left[\left\{\mathrm{Eu}(\mathrm{dbm})_{3}\right\}_{2}(\mu\right.$-bpm) $] 10$ wt.- $\% / \mathrm{LiF} / \mathrm{Al}(\mathrm{ITO}=$ Indium-tin oxide, $\quad$ PEDOT $=[$ poly $($ styrenesulfonate $)$-doped $\operatorname{poly}(3,4-$ ethylenedioxythiophene), $\quad \mathrm{PVK}=\operatorname{poly}(9$-vinylcarbazole $)$, PBD = 2-(4-biphenylyl)-5-(4-tert-butylphenyl)-1,3,4-oxadiazole) [72]. PVK and PBD were used as a hole-transporting matrix and an electron-transporting and hole-blocking material, respectively. The emitting layer was deposited from a 1,2-dichloroethane solution, and PVK was used as the matrix. Red emission was obtained from this device which showed relatively low performances, as a brightness of $25 \mathrm{~cd} / \mathrm{m}^{2}$ at $16 \mathrm{~V}$ and an external quantum efficiency of $0.021 \%$ was reported. Attempts to characterize a similar device with $\left[\left\{\mathrm{Eu}(\mathrm{tta})_{3}\right\}_{2}(\mu\right.$-bpm) $]$ failed as the quality of the films formed with complexes comprising ttas were described to be too bad and many pin-holes and dark spots were formed immediately when the devices were operated. The second report described the use of $\left[\left\{\mathrm{Eu}(\mathrm{acac})_{3}\right\}_{2}(\mu\right.$-bpm $\left.)\right]$ and $\left[\left\{\mathrm{Eu}(\mathrm{tta})_{3}\right\}_{2}(\mu\right.$-bpm $\left.)\right]$ in devices built by thermal evaporation [88]. These multilayered devices were built with the structure: ITO/CuPc/ $\alpha-\mathrm{NPB} / \mathrm{CBP}\left[\left\{\operatorname{Eu}(\beta)_{3}\right\}_{2}(\mu-\right.$ $\mathrm{bpm})] / \mathrm{BCP} / \mathrm{Alq}_{3} / \mathrm{LiF} / \mathrm{Al}$ with $\mathrm{CuPc}$ (copper phthalocyanine) 


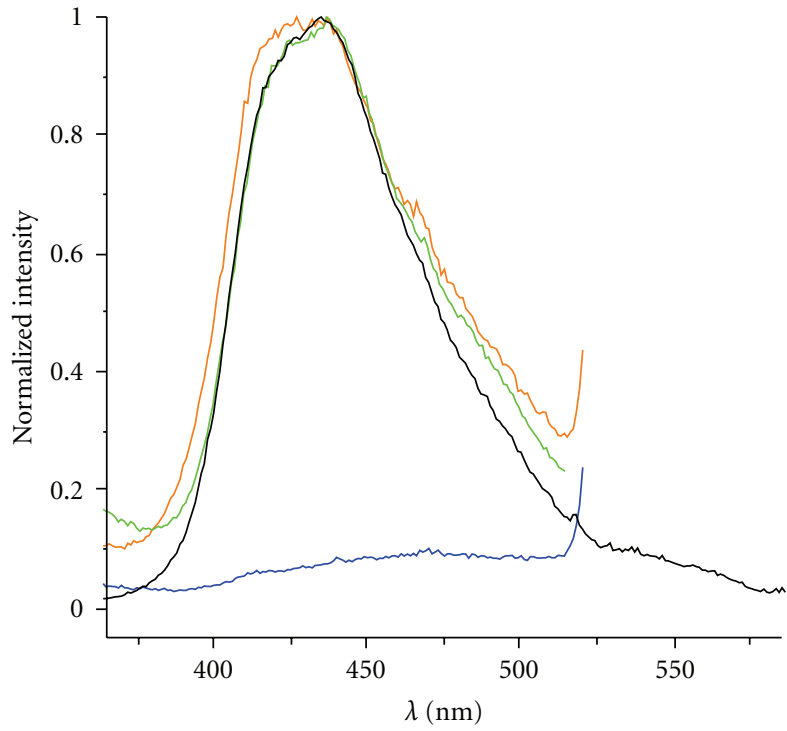

(a)

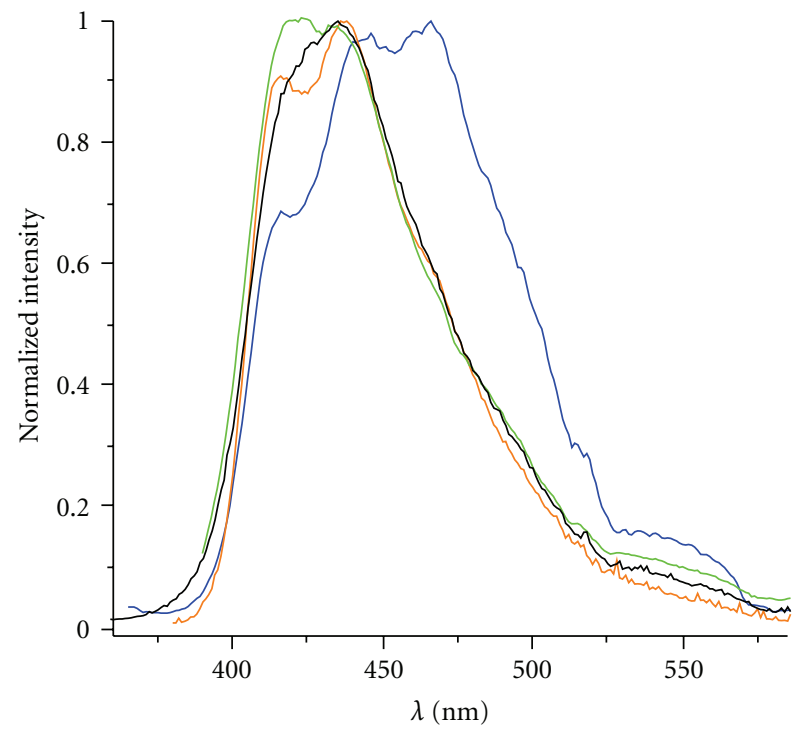

(b)

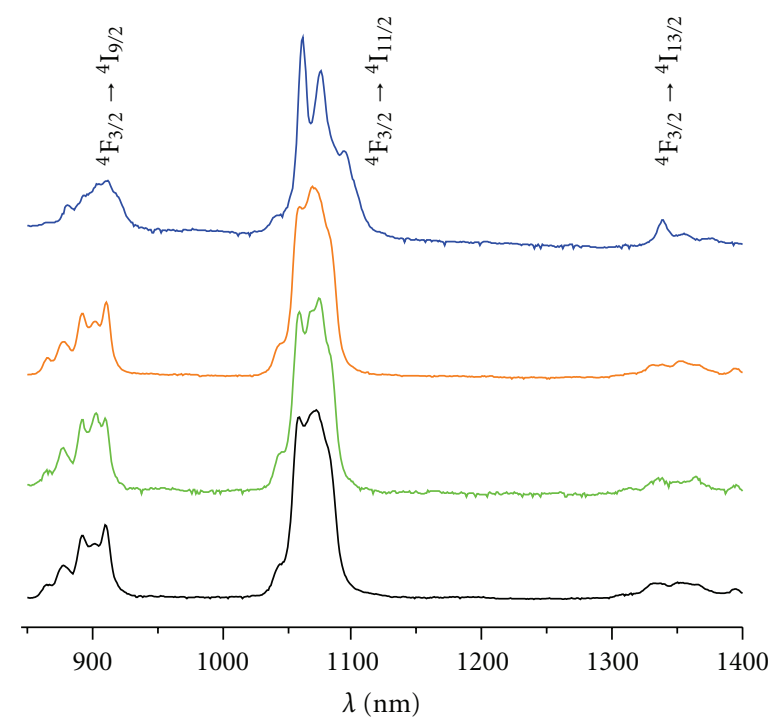

(c)

Figure 7: (a) Visible emission spectra of the complexes $\left[\left\{\mathrm{Nd}(\mathrm{dbm})_{3}(\mathrm{THF})\right\}_{2}(\mu\right.$-bpm) $]$ (blue, $\left.\lambda_{\text {exc }}=270 \mathrm{~nm}\right),\left[\left\{\mathrm{Nd}(\mathrm{bta})_{3}(\mathrm{MeOH})\right\}_{2}(\mu\right.$ $\mathrm{bpm})] \cdot \mathrm{bpm}(3 \cdot \mathrm{bpm})$ (orange, $\left.\lambda_{\text {exc }}=270 \mathrm{~nm}\right),\left[\left\{\mathrm{Nd}(\mathrm{tta})_{3}\right\}_{2}(\mu-\mathrm{bpm})\right]_{\infty}\left(\right.$ green, $\left.\lambda_{\text {exc }}=270 \mathrm{~nm}\right)$, and $\left[\mathrm{Nd}(\mathrm{nta})_{3}(\mathrm{bpm})\right]_{x}\left(\mathrm{black}, \lambda_{\mathrm{exc}}=260 \mathrm{~nm}\right)$; (b) visible emission spectra of $\left[\left\{\mathrm{Nd}(\mathrm{dbm})_{3}(\mathrm{THF})\right\}_{2}(\mu\right.$-bpm) $]$ (blue, $\left.\lambda_{\mathrm{exc}}=353 \mathrm{~nm}\right),\left[\left\{\mathrm{Nd}(\mathrm{bta})_{3}(\mathrm{MeOH})\right\}_{2}(\mu\right.$-bpm) $] \cdot \mathrm{bpm}(3 \cdot \mathrm{bpm})(\mathrm{orange}$, $\left.\lambda_{\text {exc }}=370 \mathrm{~nm}\right),\left[\left\{\mathrm{Nd}(\mathrm{tta})_{3}\right\}_{2}(\mu-\mathrm{bpm})\right]_{\infty}\left(\right.$ green, $\left.\lambda_{\text {exc }}=370 \mathrm{~nm}\right)$ and $\left[\mathrm{Nd}(\mathrm{nta})_{3}(\mathrm{bpm})\right]_{x}\left(\right.$ black, $\left.\lambda_{\text {exc }}=333 \mathrm{~nm}\right) ;(\mathrm{c})$ near-IR emission spectra of $\left[\left\{\mathrm{Nd}(\mathrm{dbm})_{3}(\mathrm{THF})\right\}_{2}(\mu\right.$-bpm) $]$ (blue, $\left.\lambda_{\text {exc }}=370 \mathrm{~nm}\right),\left[\mathrm{Nd}(\mathrm{bta})_{3}(\mathrm{MeOH})_{2}(\mu-\mathrm{bpm})\right] \cdot \mathrm{bpm}(3 \cdot \mathrm{bpm})\left(\right.$ orange, $\left.\lambda_{\text {exc }}=370 \mathrm{~nm}\right),\left[\left\{\mathrm{Nd}(\mathrm{tta})_{3}\right\}_{2}(\mu-\right.$ $\mathrm{bpm})]_{\infty}\left(\right.$ green, $\left.\lambda_{\text {exc }}=343 \mathrm{~nm}\right)$ and $\left[\mathrm{Nd}(\mathrm{nta})_{3}(\mathrm{bpm})\right]_{x}\left(\right.$ black, $\left.\lambda_{\text {exc }}=370 \mathrm{~nm}\right)$ in the solid state.

as a hole injecting layer, $\alpha$-NPB $\left(4,4^{\prime}\right.$-bis[N-(1-naphthyl)$\mathrm{N}$-phenylamino]biphenyl) as a hole transporting layer, CBP $\left(4,4^{\prime}-\mathrm{N}, \mathrm{N}^{\prime}\right.$-dicarbazole-biphenyl) as the matrix, BCP $(2,9-$ dimethyl-4,7-diphenyl-1,10-phenanthroline) as a hole blocking layer, $\mathrm{Alq}_{3}$ (Aluminium tris(8-hydroxyquinolinate)) as an electron injecting layer, and $\mathrm{LiF} / \mathrm{Al}$ as the top cathode. Devices with both tta and acac ligands afforded white light. The electroluminescence spectrum of the device made with $\left[\left\{\mathrm{Eu}(\mathrm{tta})_{3}\right\}_{2}(\mu\right.$-bpm) $]$ is reported on Figure 9. This surprising result was shown to be the consequence of the simultaneous yellow-green emission of an exciplex formed between the dopant and CBP and the red emission from the $\mathrm{Eu}^{3+}$ ion. Performances of these OLEDs were, though low, better than that of the previously described devices with $\left[\left\{\mathrm{Eu}(\mathrm{dbm})_{3}\right\}_{2}(\mu\right.$-bpm $\left.)\right]$. The maximum brightness for the device made with $\left[\left\{\mathrm{Eu}(\mathrm{tta})_{3}\right\}_{2}(\mu\right.$-bpm) $]$ was found to be $83 \mathrm{~cd} / \mathrm{m}^{2}$ at $13.9 \mathrm{~V}$, and the external quantum efficiency was $0.09 \%$. 


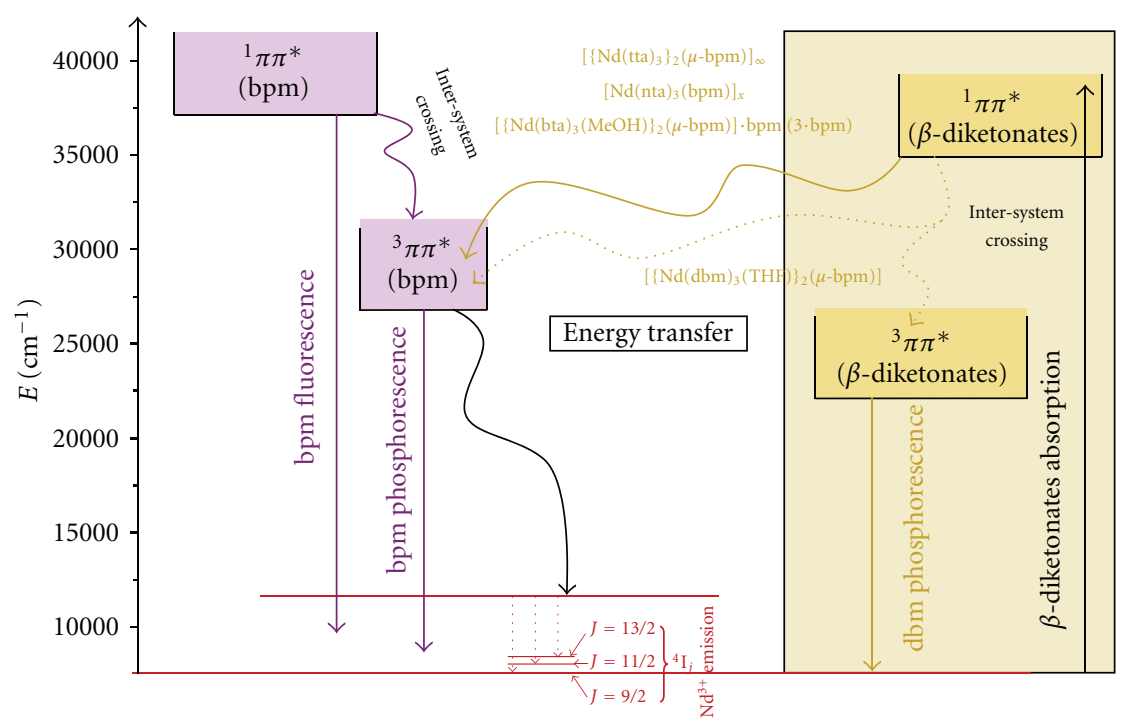

FIGURE 8: Relative energetic positions of the lowest singlet and triplet excited states of bpm (left) and the $\beta$-diketonates dbm, bta, tta, and nta, and possible energy migration pathways and transfers occurring in the complexes $\left[\left\{\mathrm{Nd}(\mathrm{dbm})_{3}(\mathrm{THF})\right\}_{2}(\mu\right.$-bpm $\left.)\right],\left[\left\{\mathrm{Nd}(\mathrm{bta})_{3}(\mathrm{MeOH})\right\}_{2}(\mu-\right.$ bpm) $] \cdot \operatorname{bpm}(3 \cdot \mathrm{bpm}),\left[\left\{\mathrm{Nd}(\mathrm{tta})_{3}\right\}_{2}(\mu-\mathrm{bpm})\right]_{\infty}$, and $\left[\mathrm{Nd}(\mathrm{nta})_{3}(\mathrm{bpm})\right]_{x}$.

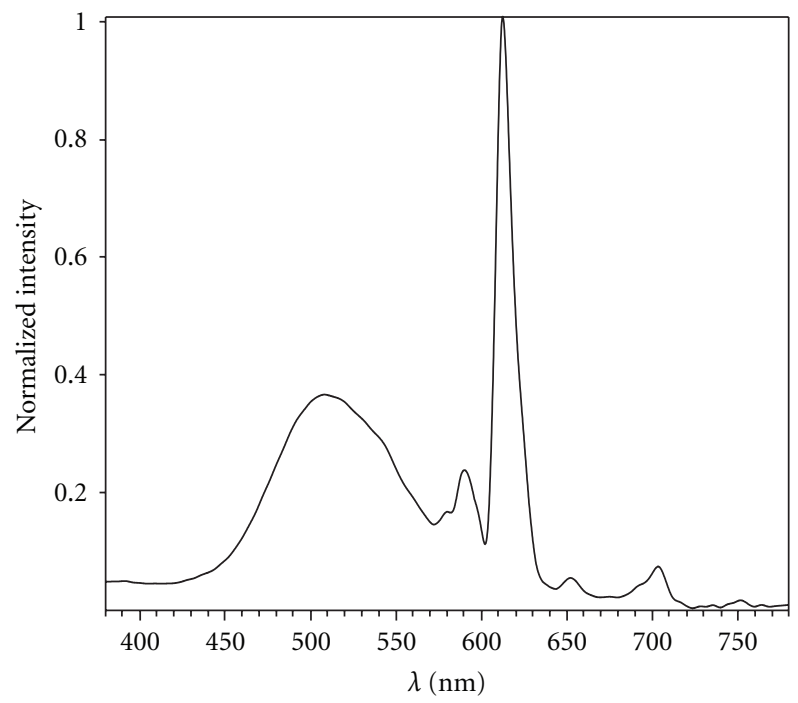

FIGURE 9: Normalized electroluminescence spectrum of the OLED made with $\left[\left\{\mathrm{Eu}(\mathrm{tta})_{3}\right\}_{2}(\mu\right.$-bpm $\left.)\right]$ as the dopant.

These complexes in which bpm connects two paramagnetic metal ions are also interesting candidates for the study of magnetic interactions between two adjacent ions. Investigations in the field of molecular magnetism made on lanthanides complexes comprising bpm as a bridging ligands will now be reported.

2.2.2. Magnetic Properties of Complexes with bpm Bridges. As described above, and due to its bridging coordination mode, the $2,2^{\prime}$-bipyrimidine can connect metal ions to afford a great variety of structures ranging from bimetallic complexes to coordination polymers of different dimensionalities. This is of importance in view of designing magnetic systems. Indeed, bpm was shown to allow an electronic interaction between two $3 d$ transition metal ions in polymetallic systems. For instance, bimetallic compounds made up of systems such $\left[\mathrm{Cu}^{\mathrm{II}}-\mathrm{Cu}^{\mathrm{II}}{ }_{2}(\mu-\mathrm{bpm})\right][89], \quad\left[\left\{\mathrm{Fe}^{\mathrm{II}}-\mathrm{Cu}^{\mathrm{II}}\right\}_{2}(\mu-\right.$ bpm) $][90],\left[\left\{\mathrm{Fe}^{\mathrm{III}}-\mathrm{Fe}^{\mathrm{III}}\right\}_{2}(\mu-\mathrm{bpm})\right][91],\left[\left\{\mathrm{Fe}^{\mathrm{III}}-\mathrm{Fe}^{\mathrm{II}}\right\}_{2}(\mu-\right.$ bpm) $]$ [92], $\left[\left\{\mathrm{Fe}^{\mathrm{II}}-\mathrm{Cu}^{\mathrm{II}}\right\}_{2}(\mu-\mathrm{bpm})\right]$ [93], [\{ $\left.\mathrm{Co}^{\mathrm{II}}-\mathrm{Co}^{\mathrm{II}}\right\}_{2}(\mu-$ bpm)] [94] were studied for their magnetic properties. Also, coordination polymers comprising bpm were investigated. Monodimensional $\left[\left\{\mathrm{Mn}^{\mathrm{II}}-\mathrm{Mn}^{\mathrm{II}}\right\}_{2}(\mu-\mathrm{bpm})\right]_{n}[95]$ and $\left[\left\{\mathrm{Co}^{\mathrm{II}}-\mathrm{Co}^{\mathrm{II}}\right\}_{2}(\mu \text {-bpm })\right]_{n}[94,96]$ systems were investigated, as well as bidimensional $\left[\left\{\mathrm{Cu}^{\mathrm{I}}-\mathrm{Cu}^{\mathrm{I}}\right\}_{2}(\mu-\mathrm{bpm})\right]_{n}$ [97] and $\left[\left\{\mathrm{Ni}^{\mathrm{II}}-\mathrm{Ni}^{\mathrm{II}}\right\}_{2}(\mu-\mathrm{bpm})\right]_{n} \quad[98]$, and tridimensional $\left[\left\{\mathrm{Cu}^{\mathrm{II}}-\right.\right.$ $\left.\mathrm{Cu}^{\mathrm{II}}\right\}_{2}(\mu$-bpm)] [98] coordination polymers built up with $\mathrm{bpm}$. All these compounds show antiferromagnetic couplings between two metal ions through the bpm bridge.

The use of bpm with $4 f$ ions in the field of molecular magnetism is also a recent field of investigations. In consequence, very few magnetostructural studies in which two lanthanide ions are directly connected and which show electronic interaction through $\mathrm{bpm}$ have been reported. Interactions between $\mathrm{Yb}^{3+}$ ions [82], two $\mathrm{Nd}^{3+}$ ions and two $\mathrm{Gd}^{3+}$ ions [69], and $\mathrm{Ce}^{3+}$ ions [83] were described. In all cases, variable-temperature magnetic susceptibility measurements have revealed that the interaction was weakly antiferromagnetic with values of $-0.0195(4)$ and $-1.1 \mathrm{~cm}^{-1}$ for the $J_{\mathrm{Gd}-\mathrm{Gd}}$ and $J_{\mathrm{Ce}-\mathrm{Ce}}$ coupling constants in $\left[\left\{\mathrm{Gd}(\mathrm{X})_{3}\right\}_{2}(\mu\right.$-bpm $\left.)\right]$ (X = dimethyl-N-trichloracetylamidophosphato) [69], and $\left[\left\{\mathrm{Ce}(\mathrm{dmf})_{3}\left(\mathrm{H}_{2} \mathrm{O}\right)_{4}\right\}_{2}(\mu \text {-bpm })\right]^{3+}[\mathrm{W}(\mathrm{CN}) 8]_{2}{ }^{3-} \cdot 3 \mathrm{H}_{2} \mathrm{O}$, and $\left[\left\{\mathrm{Ce}(\mathrm{dmso})_{4}\left(\mathrm{H}_{2} \mathrm{O}\right)_{2}\right\}_{2}(\mu-\mathrm{bpm})\right]^{3+}[\mathrm{W}(\mathrm{CN}) 8]_{2}{ }^{3-} \cdot 4 \mathrm{H}_{2} \mathrm{O}$, respectively [83]. 
The $\mathrm{Gd}^{3+}$ ion has been the most investigated trivalent lanthanide ion for magnetic purpose as it is a highly paramagnetic ion that possesses seven unpaired electrons. The divalent europium ion is isoelectronic to $\mathrm{Gd}^{3+}$. However, because of the easy oxidation to $\mathrm{Eu}^{3+}$ and the resulting instability of the $\mathrm{Eu}^{2+}$ complexes, it has not been paid a real attention to the latter in the field of molecular magnetism. We have reported the sole example to date of a magnetic interaction between two $\mathrm{Eu}^{2+}$ ions in compounds formed with organic ligands [84]. These compounds were the two 1D coordination polymers of formulae $\left(\left[\left\{\mathrm{Eu}\left(\mathrm{H}_{2} \mathrm{O}\right)_{3}\right\}_{2}(\mu-\mathrm{bpm})\right]^{2+}[\mathrm{I}]_{2}{ }^{2-} \cdot 0.5 \mathrm{bpm}\right)_{\infty}$ and $\left(\left[\{\mathrm{EuI}(\mathrm{MeOH})\}_{2}(\mu \text {-bpm })\right]^{+}[\mathrm{I}]^{-}\right)_{\infty}$, respectively, and the 3D framework $\left[\{\mathrm{Eu}\}_{2}(\mu-\mathrm{Cl})_{2}(\mu \text {-bpm }) \cdot 0.5 \mathrm{MeOH}\right]_{\infty}$. Weak ferromagnetic interactions occurring between two $\mathrm{Eu}^{2+}$ ions separated by about $7 \AA$ by the bridging bpm ligand were described. The coupling constant was found to be positive and values of +0.02 and $+0.01 \mathrm{~cm}^{-1}$ were determined for $\left(\left[\left\{\mathrm{Eu}\left(\mathrm{H}_{2} \mathrm{O}\right)_{3}\right\}_{2}(\mu \text {-bpm })\right]^{2+}[\mathrm{I}]_{2}{ }^{2-} \cdot 0.5 \mathrm{bpm}\right)_{\infty}$ and $\left(\left[\{\mathrm{EuI}(\mathrm{MeOH})\}_{2}(\mu \text {-bpm })\right]^{+}[\mathrm{I}]^{-}\right)_{\infty}$, respectively. The values of the effective moments deduced from experimental data were found to be 7.8, 7.7, and $7.7 \mu_{\mathrm{B}}$ for $\left[\{\mathrm{Eu}\}_{2}(\mu-\mathrm{Cl})_{2}(\mu \text {-bpm }) \cdot 0.5 \mathrm{MeOH}\right]_{\infty},\left(\left[\left\{\mathrm{Eu}\left(\mathrm{H}_{2} \mathrm{O}\right)_{3}\right\}_{2}(\mu-\right.\right.$ $\left.\mathrm{bpm})]^{2+}[\mathrm{I}]_{2}{ }^{2-} \cdot 0.5 \mathrm{bpm}\right)_{\infty}$, and $\left(\left[\{\mathrm{EuI}(\mathrm{MeOH})\}_{2}(\mu-\mathrm{bpm})\right]^{+}\right.$ $\left.[\mathrm{I}]^{-}\right)_{\infty}$, respectively. As the theoretical value for the free $\mathrm{Eu}^{\mathrm{II}}$ ion amounts to $7.9 \mu_{\mathrm{B}}$, these experimental values definitely confirmed the presence of the europium ions in the divalent state in the three compounds.

\section{Conclusion}

This review intended to emphasize the recent interest devoted to the use of 2,2' -bipyrimidine in designing molecular lanthanide complexes as well as lanthanide-containing hybrid organic-inorganic materials of various dimensionalities and for the role it plays on the solid-state physical properties of these materials. All the studies reported to date show the great potential that bpm can bring to lanthanide chemistry and physics. The wealth of structures that can generate this neutral Lewis base is due to the two coordination modes this ligand can adopt with the lanthanide ions. Indeed, compounds with terminal and bridging bpm ligands were isolated and structurally characterized. It is anticipated that some of these compounds could serve as molecular building blocks for more sophisticated architectures with improved physical properties. In particular, the simultaneous use of bpm with other bridging ligands such as $\mathrm{CN}^{-}[65,99-102], \mathrm{Cl}^{-}[84]$, or other bridging ligands allowing an electronic interaction between two metal ions can lead to heteropolymetallic metal-organic frameworks with interesting magnetic properties.

It is to be hoped that the use of $2,2^{\prime}$-bipyrimidine in lanthanide chemistry will be more investigated for designing original lanthanide-containing frameworks and molecular materials in a close future. Much remains to be made, as, for instance, no investigation on the magnetic properties of mixed $d-f$ complexes structurally characterized in which transition metals and lanthanide ions are directly connected by bpm have been reported to date. Also, the very efficient sensitization of the luminescence of both the $\mathrm{Tb}^{3+}$ and $\mathrm{Eu}^{3+}$ ions by bpm is worth to be exploited for designing new highly emissive solid state hybrid materials.

\section{Acknowledgments}

The author would like to thank the CEA, the CNRS, and the Ecole polytechnique for the past and present support of his research, as well as colleagues whose names appear in the publications related to the use of $2,2^{\prime}$-bipyrimidine in lanthanide chemistry he has coauthored for their contribution to his work devoted to this topic. In particular, he thanks Dr. P. Thuéry for doing Figure 3.

\section{References}

[1] A. Razavi and U. Thewalt, "Site selective ligand modification and tactic variation in polypropylene chains produced with metallocene catalysts," Coordination Chemistry Reviews, vol. 250, no. 1-2, pp. 155-169, 2006.

[2] H. M. Sun, S. Chen, Y. Yao, Q. Shen, and K. Yu, "Homoleptic lanthanide metallocenes and their derivates: syntheses, structural characterization and their catalysis for ring-opening polymerization of $\varepsilon$-caprolactone," Applied Organometallic Chemistry, vol. 20, no. 5, pp. 310-314, 2006.

[3] H. Yasuda and G. Desurmont, "Block copolymerizations of higher 1-olefins with traditional polar monomers using metallocene-type single component lanthanide initiators," Polymer International, vol. 53, no. 8, pp. 1017-1024, 2004.

[4] S. Kaita, Y. Doi, K. Kaneko, A. C. Horiuchi, and Y. Wakatsuki, "An efficient gadolinium metallocene-based catalyst for the synthesis of isoprene rubber with perfect 1,4-cis microstructure and marked reactivity difference between lanthanide metallocenes toward dienes as probed by butadiene - Isoprene copolymerization catalysis," Macromolecules, vol. 37, no. 16, pp. 5860-5862, 2004.

[5] J. Jenter, N. Meyer, P. W. Roesky, S. K. H. Thiele, G. Eickerling, and W. Scherer, "Borane and borohydride complexes of the rare-earth elements: synthesis, structures, and butadiene polymerization catalysis," Chemistry, vol. 16, no. 18, pp. 5472-5480, 2010.

[6] M. J. Vitorino, T. Devic, M. Tromp, G. Férey, and M. Visseaux, "Lanthanide metal-organic frameworks as zieglernatta catalysts for the selective polymerization of isoprene," Macromolecular Chemistry and Physics, vol. 210, no. 22, pp. 1923-1932, 2009.

[7] J. Thuilliez, V. Monteil, R. Spitz, and C. Boisson, "Alternating copolymerization of ethylene and butadiene with a neodymocene catalyst," Angewandte Chemie, vol. 44, no. 17, pp. 2593-2596, 2005.

[8] K. Mikami, M. Terada, and H. Matsuzawa, "Asymmetric catalysis by lanthanide complexes," Angewandte Chemie, vol. 41, no. 19, pp. 3555-3571, 2002.

[9] Z. Hou and Y. Wakatsuki, "Recent developments in organolanthanide polymerization catalysts," Coordination Chemistry Reviews, vol. 231, no. 1-2, pp. 1-22, 2002.

[10] S. Hong and T. J. Marks, "Organolanthanide-catalyzed hydroamination," Accounts of Chemical Research, vol. 37, no. 9, pp. 673-686, 2004.

[11] M. Shibasaki and N. Yoshikawa, "Lanthanide complexes in multifunctional asymmetric catalysis," Chemical Reviews, vol. 102, no. 6, pp. 2187-2209, 2002. 
[12] J. Inanaga, H. Furuno, and T. Hayano, "Asymmetric catalysis and amplification with chiral lanthanide complexes," Chemical Reviews, vol. 102, no. 6, pp. 2211-2225, 2002.

[13] A. Yamaguchi, S. Matsunaga, and M. Shibasaki, "Direct catalytic asymmetric Mannich-type reactions of $\gamma$-butenolides: effectiveness of Brønsted acid in chiral metal catalysis," Organic Letters, vol. 10, no. 11, pp. 2319-2322, 2008.

[14] T. Nitabaru, A. Nojiri, M. Kobayashi, N. Kumagai, and M. Shibasaki, "Anti-selective catalytic asymmetric nitroaldol reaction via a heterobimetallic heterogeneous catalyst," Journal of the American Chemical Society, vol. 131, no. 38, pp. 13860-13869, 2009.

[15] S. Kobayashi, T. Hamada, S. Nagayama, and K. Manabe, "Lanthanide trifluoromethanesulfonate-catalyzed asymmetric aldol reactions in aqueous media," Organic Letters, vol. 3, no. 2, pp. 165-167, 2001.

[16] S. Kobayashi, "Scandium triflate in organic synthesis," European Journal of Organic Chemistry, no. 1, pp. 15-27, 1999.

[17] M. Shibasaki and N. Yoshikawa, "Lanthanide complexes in multifunctional asymmetric catalysis," Chemical Reviews, vol. 102, no. 6, pp. 2187-2209, 2002.

[18] K. Nwe, C. M. Andolina, and J. R. Morrow, "Tethered dinuclear europium(III) macrocyclic catalysts for the cleavage of RNA," Journal of the American Chemical Society, vol. 130, no. 44, pp. 14861-14871, 2008.

[19] J. R. Morrow, "Speed limits for artificial ribonucleases," Comments on Inorganic Chemistry, vol. 29, no. 5-6, pp. 169188, 2008.

[20] A. M. Fanning, S. E. Plush, and T. Gunnlaugsson, "Tuning the properties of cyclen based lanthanide complexes for phosphodiester hydrolysis; the role of basic cofactors," Chemical Communications, no. 36, pp. 3791-3793, 2006.

[21] A. Kuzuya, K. MacHida, T. Sasayama, Y. Shi, R. Mizoguchi, and M. Komiyama, "Lanthanide ions as versatile catalyst in biochemistry: efficient site-selective scission of RNA by free lanthanide ions," Journal of Alloys and Compounds, vol. 408412, pp. 396-399, 2006.

[22] C. A. Chang, H. W. Bo, and Y. K. Bu, "Macrocyclic lanthanide complexes as artificial nucleases and ribonucleases: effects of $\mathrm{pH}$, metal ionic radii, number of coordinated water molecules, charge, and concentrations of the metal complexes," Inorganic Chemistry, vol. 44, no. 19, pp. 66466654, 2005.

[23] T. Gunnlaugsson, R. J. H. Davies, P. E. Kruger et al., "Cyclen based lanthanide ion ribonuclease mimics: the effect of pyridine cofactors upon phosphodiester HPNP hydrolysis," Tetrahedron Letters, vol. 46, no. 21, pp. 3761-3766, 2005.

[24] K. Matsumura and M. Komiyama, "Enormously fast RNA hydrolysis by Lanthanide(III) ions under physiological conditions: eminent candidates for novel tools of biotechnology," Journal of Biochemistry, vol. 122, no. 2, pp. 387-394, 1997.

[25] B. Zhu, Z. Q. Wang, X. M. Li, D. Q. Zhao, and J. Z. Ni, "Lanthanide metal complexes for the hydrolysis of ribonucleoside $3^{\prime}, 5^{\prime}$-cyclic phosphate and deoxyribonucleoside 3',5'cyclic phosphate," Journal of Molecular Catalysis A, vol. 118, no. 1, pp. L5-L7, 1997.

[26] E. R. Farquhar, J. P. Richard, and J. R. Morrow, "Formation and stability of mononuclear and dinuclear $\mathrm{Eu}(\mathrm{III}) \mathrm{com}$ plexes and their catalytic reactivity toward cleavage of an RNA analog," Inorganic Chemistry, vol. 46, no. 17, pp. 71697177, 2007.

[27] R. L. Carlin, Magnetochemistry, Springer, New York, NY, USA, 1986.
[28] R. B. Lauffer, "Paramagnetic metal complexes as water proton relaxation agents for NMR imaging: theory and design," Chemical Reviews, vol. 87, no. 5, pp. 901-927, 1987.

[29] S. Aime, D. D. Castelli, S. G. Crich, E. Gianolio, and E. Terreno, "Pushing the sensitivity envelope of lanthanidebased magnetic resonance imaging (MRI) contrast agents for molecular imaging applications," Accounts of Chemical Research, vol. 42, no. 7, pp. 822-831, 2009.

[30] P. Caravan, J. J. Ellison, T. J. McMurry, and R. B. Lauffer, "Gadolinium(III) chelates as MRI contrast agents: structure, dynamics, and applications," Chemical Reviews, vol. 99, no. 9, pp. 2293-2352, 1999.

[31] E. Tóth, L. Helm, and A. E. Merbach, "Relaxivity of MRI contrast agents," Topics in Current Chemistry, vol. 221, pp. 61-101, 2002.

[32] A. Datta and K. N. Raymond, "Gd-hydroxypyridinone (HOPO)-based high-relaxivity magnetic resonance imaging (MRI) contrast agents," Accounts of Chemical Research, vol. 42, no. 7, pp. 938-947, 2009.

[33] C. F. G. C. Geraldes, NMR in Supramolecular Chemistry, Kluwer Academic Publishers, Amsterdam, The Netherlands, 1999.

[34] X. C. Su, H. Liang, K. V. Loscha, and G. Otting, " $\left[\operatorname{Ln}(\mathrm{DPA})_{3}\right]^{3-}$ is a convenient paramagnetic shift reagent for protein NMR studies," Journal of the American Chemical Society, vol. 131, no. 30, pp. 10352-10353, 2009.

[35] M. Kagawa, Y. Machida, H. Nishi, and J. Haginaka, "Enantiomeric purity determination of acetyl-L-carnitine by NMR with chiral lanthanide shift reagents," Journal of Pharmaceutical and Biomedical Analysis, vol. 38, no. 5, pp. 918-923, 2005.

[36] R. S. Dickins and A. Badari, "A new chiral lanthanide NMR probe for the determination of the enantiomeric purity of $\alpha$-hydroxy acids and the absolute configuration of $\alpha$-amino acids in water," Dalton Transactions, no. 25, pp. 3088-3096, 2006.

[37] H. Tsukube, S. Shinoda, J. Uenishi et al., "Molecular recognition with lanthanide(III) tris( $\beta$-diketonate) complexes: extraction, transport, and chiral recognition of unprotected amino acids," Inorganic Chemistry, vol. 37, no. 7, pp. 15851591, 1998.

[38] N. S. Sudhindra, M. A. Gagnani, D. M. Indira, and R. S. Shukla, "Biological and clinical aspects of lanthanide coordination compounds," Bioinorganic Chemistry and Applications, vol. 2, no. 3-4, pp. 155-192, 2004.

[39] A. Bencini, C. Benelli, A. Caneschi, R. L. Carlin, A. Dei, and D. Gatteschi, "Crystal and molecular structure of and magnetic coupling in two complexes containing gadolinium(III) and copper(II) ions," Journal of the American Chemical Society, vol. 107, no. 26, pp. 8128-8136, 1985.

[40] R. Sessoli and A. K. Powell, "Strategies towards single molecule magnets based on lanthanide ions," Coordination Chemistry Reviews, vol. 253, no. 19-20, pp. 2328-2341, 2009.

[41] A. Mishra, W. Wernsdorfer, K. A. Abboud, and G. Christou, "Initial observation of magnetization hysteresis and quantum tunneling in mixed manganese-lanthanide singlemolecule magnets," Journal of the American Chemical Society, vol. 126, no. 48, pp. 15648-15649, 2004.

[42] S. Osa, T. Kido, N. Matsumoto, N. Re, A. Pochaba, and J. Mrozinski, "A tetranuclear $3 \mathrm{~d}-4 \mathrm{f}$ single molecule magnet: $\left[\mathrm{Cu}^{I I} \mathrm{LTb}^{I I I}(\mathrm{hfac})_{2}\right]_{2}$," Journal of the American Chemical Society, vol. 126, no. 2, pp. 420-421, 2004.

[43] J. P. Costes, F. Dahan, and W. Wernsdorfer, "Heterodinuclear $\mathrm{Cu}-\mathrm{Tb}$ single-molecule magnet," Inorganic Chemistry, vol. 45, no. 1, pp. 5-7, 2006. 
[44] P. H. Lin, T. J. Burchell, L. Ungur, L. F. Chibotaru, W. Wernsdorfer, and M. Murugesu, "A polinuclear lanthanide single-molecule magnet with a record anisotropic barrier," Angewandte Chemie, vol. 48, no. 50, pp. 9489-9492, 2009.

[45] J. X. Xu, Y. Ma, D. Z. Liao et al., "Four new lanthanide-nitronyl nitroxide $(\operatorname{Ln}(\mathrm{III})=\operatorname{Pr}(\mathrm{III}), \mathrm{Sm}(\mathrm{III}), \mathrm{Eu}(\mathrm{III}), \operatorname{Tm}(\mathrm{III})$ complexes and $\mathrm{a} \mathrm{Tb}(\mathrm{III})$ complex exhibiting single-molecule magnet behavior," Inorganic Chemistry, vol. 48, no. 18, pp. 8890-8896, 2009.

[46] K. Bernot, J. Luzon, L. Bogani et al., "Magnetic anisotropy of dysprosium(III) in a low-symmetry environment: a theoretical and experimental investigation," Journal of the American Chemical Society, vol. 131, no. 15, pp. 5573-5579, 2009.

[47] Y. Ma and Y. Wang, "Recent advances in the sensitized luminescence of organic europium complexes," Coordination Chemistry Reviews, vol. 254, no. 9-10, pp. 972-990, 2010.

[48] S. V. Eliseeva and J.-C. G. Bünzli, "Lanthanide luminescence for functional materials and bio-sciences," Chemical Society Reviews, vol. 39, no. 1, pp. 189-227, 2010.

[49] L. Armelao, S. Quici, F. Barigelletti et al., "Design of luminescent lanthanide complexes: from molecules to highly efficient photo-emitting materials," Coordination Chemistry Reviews, vol. 254, no. 5-6, pp. 487-505, 2010.

[50] I. Hemmilä, T. Ståhlberg, and P. Mottram, Bioanalytical Applications of Labelling Technologies, Wallac Oy, Turku, Finland, 2nd edition, 1995.

[51] I. Hemmilä, Applications of Fluorescence in Immunoassays, Wiley Interscience, New York, NY, USA, 1st edition, 1991.

[52] D. Parker and J. Yu, "A pH-insensitive, ratiometric chemosensor for citrate using europium luminescence," Chemical Communications, no. 25, pp. 3141-3143, 2005.

[53] B. K. McMahon and T. Gunnlaugsson, "Lanthanide luminescence sensing of copper and mercury ions using an iminodiacetate-based $\mathrm{Tb}$ (III)-cyclen chemosensor," Tetrahedron Letters, vol. 51, no. 41, pp. 5406-5410, 2010.

[54] C. M. G. Dos Santos and T. Gunnlaugsson, "The recognition of anions using delayed lanthanide luminescence: the use of $\mathrm{Tb}$ (iii) based urea functionalised cyclen complexes," Dalton Transactions, no. 24, pp. 4712-4721, 2009.

[55] S. E. Plush and T. Gunnlaugsson, "Luminescent sensing of dicarboxylates in water by a bismacrocyclic dinuclear $\mathrm{Eu}$ (III) conjugate," Organic Letters, vol. 9, no. 10, pp. 1919-1922, 2007.

[56] J. P. Leonard, C. M. G. Dos Santos, S. E. Plush, T. McCabe, and T. Gunnlaugsson, "pH driven self-assembly of a ternary lanthanide luminescence complex: the sensing of anions using a $\beta$-diketonate-Eu(III) displacement assay," Chemical Communications, no. 2, pp. 129-131, 2007.

[57] T. Gunnlaugsson, M. Glynn, G. M. Tocci, P. E. Kruger, and F. M. Pfeffer, "Anion recognition and sensing in organic and aqueous media using luminescent and colorimetric sensors," Coordination Chemistry Reviews, vol. 250, no. 23-24, pp. 3094-3117, 2006.

[58] K. Binnemans, "Rare earths $\beta$-diketonates," in Handbook on the Physics and Chemistry of Rare Earths, K. A. Gschneidner Jr., J. C. G. Bünzli, and V. K. Pescharsky, Eds., vol. 35, pp. 107-272, Elsevier, Amsterdam, The Netherlands, 2005.

[59] N. Filipescu, W. F. Sager, and F. A. Serafin, "Substituent effects on intramolecular energy transfer-II. Fluorescence spectra of europium and terbium $\beta$-diketone chelates," Journal of Physical Chemistry, vol. 68, no. 11, pp. 3324-3346, 1964.

[60] M. L. Bhaumik, "Rare-earth chelate vapour," Journal of Inorganic and Nuclear Chemistry, vol. 27, no. 1, p. 261, 1965.
[61] O. L. Malta, H. F. Brito, J. F. S. Menezes, F. R. Gonçalves e Silva, C. De Mello Donegá, and S. Alves, "Experimental and theoretical emission quantum yield in the compound $\mathrm{Eu}$ (thenoyltrifluoroacetonate) ${ }_{3} .2$ (dibenzyl sulfoxide)," Chemical Physics Letters, vol. 282, no. 3-4, pp. 233-238, 1998.

[62] N. M. Shavaleev, Z. R. Bell, and M. D. Ward, "A simple, general synthesis of mixed d-f complexes containing both $\operatorname{Re}(\mathrm{CO}){ }_{3} \mathrm{Cl}$ (diimine) and lanthanide-tris $(\beta$-diketonate $)$ luminophores linked by bis-diimine bridging ligands," Journal of the Chemical Society, Dalton Transactions, no. 21, pp. 3925-3927, 2002.

[63] N. M. Shavaleev, G. Accorsi, D. Virgili et al., "Syntheses and crystal structures of dinuclear complexes containing d-block and f-block luminophores. Sensitization of NIR luminescence from $\mathrm{Yb}(\mathrm{III}), \mathrm{Nd}(\mathrm{III})$, and $\mathrm{Er}(\mathrm{III})$ centers by energy transfer from $\mathrm{Re}(\mathrm{I})$ - and $\mathrm{Pt}(\mathrm{II})$-bipyrimidine metal centers," Inorganic Chemistry, vol. 44, no. 1, pp. 61-72, 2005.

[64] J. M. Herrera, S. J. A. Pope, H. Adams, S. Faulkner, and M. D. Ward, "Structural and photophysical properties of coordination networks combining $\left[\mathrm{Ru}(\mathrm{Bpym})(\mathrm{CN})_{4}\right]^{2-}$ or $\left[\mathrm{Ru}(\mathrm{CN})_{42}(\mu \text {-bpym })\right]^{4-}$ anions (bpym $=2,2^{\prime}$-Bipyrimidine) with lanthanide(III) cations: sensitized near-infrared luminescence from $\mathrm{Yb}(\mathrm{III}), \mathrm{Nd}(\mathrm{III})$, and $\mathrm{Er}(\mathrm{III})$ following Ru-tolanthanide energy transfer," Inorganic Chemistry, vol. 45, no. 10, pp. 3895-3904, 2006.

[65] S. G. Baca, H. Adams, D. Sykes, S. Faulkner, and M. D. Ward, "Three-component coordination networks based on $\left[\mathrm{Ru}(\text { phen })(\mathrm{CN})_{4}\right]^{2-}$ anions, near-infrared luminescent lanthanide(iii) cations, and ancillary oligopyridine ligands: structures and photophysical properties," Dalton Transactions, no. 23, pp. 2419-2430, 2007.

[66] T. Lazarides, H. Adams, D. Sykes, S. Faulkner, G. Calogero, and M. D. Ward, "Heteronuclear bipyrimidine-bridged RuLn and Os-Ln dyads: low-energy ${ }^{3}$ MLCT states as energydonors to $\mathrm{Yb}(\mathrm{III})$ and $\mathrm{Nd}(\mathrm{III})$," Dalton Transactions, no. 5, pp. 691-698, 2008.

[67] G. Zucchi, O. Maury, P. Thuéry, and M. Ephritikhine, "Structural diversity in neodymium bipyrimidine compounds with near infrared luminescence: from mono- and binuclear complexes to metal-organic frameworks," Inorganic Chemistry, vol. 47, no. 22, pp. 10398-10406, 2008.

[68] G. Zucchi, O. Maury, P. Thuéry, F. Gumy, J. C. G. Bünzli, and M. Ephritikhine, "2,2'-Bipyrimidine as efficient sensitizer of the solid-state luminescence of lanthanide and uranyl ions from visible to near-infrared," Chemistry, vol. 15, no. 38, pp. 9686-9696, 2009.

[69] K. O. Znovjyak, O. V. Moroz, V. A. Ovchynnikov, T. Y. Sliva, S. V. Shishkina, and V. M. Amirkhanov, "Synthesis and investigations of mixed-ligand lanthanide complexes with $\mathrm{N}, \mathrm{N}^{\prime}$-dipyrrolidine- $\mathrm{N}^{\prime \prime}$-trichloracetylphosphortriamide, dimethyl-N-trichloracetylamidophosphate, $\quad 1,10$ phenanthroline and 2,2'-bipyrimidine," Polyhedron, vol. 28, no. 17, pp. 3731-3738, 2009.

[70] J. A. Fernandes, R. A. Sá Ferreira, M. Pillinger et al., "Investigation of europium(III) and gadolinium(III) complexes with naphthoyltrifluoroacetone and bidentate heterocyclic amines," Journal of Luminescence, vol. 113, no. 1-2, pp. 5063, 2005.

[71] K. Kirschbaum, A. Fratini, and S. Swavey, "The twinned crystal structure of $\mu-2,2^{\prime}$-bipyrimidine- $1 \kappa^{2} \mathrm{~N}^{1}, \mathrm{~N}^{1^{\prime}}: 2 \kappa^{2} \mathrm{~N}^{3}$, $\mathrm{N}^{3^{\prime}}$-bistris[4,4,4-trifluoro-1-(2- thienyl)butane-1,3-dionato$\left.\kappa^{2} \mathrm{O}, \mathrm{O}^{\prime}\right]$ terbium(III) ethyl acetate solvate," Acta Crystallographica Section C, vol. 62, no. 5, pp. m186-m187, 2006. 
[72] H. Jang, C. H. Shin, B. J. Jung, D. H. Kim, H. K. Shim, and Y. Do, "Synthesis and characterization of dinuclear europium complexes showing pure red electroluminescence," European Journal of Inorganic Chemistry, no. 4, pp. 718-725, 2006.

[73] S. Swavey, J. A. Krause, D. Collins, D. D'Cunha, and A. Fratini, "X-ray structure and temperature dependent luminescent properties of two bimetallic europium complexes," Polyhedron, vol. 27, no. 3, pp. 1061-1069, 2008.

[74] V. Bekiari, K. A. Thiakou, C. P. Raptopoulou, S. P. Perlepes, and P. Lianos, "Structure and photophysical behavior of 2,2 ' bipyrimidine/lanthanide ion complexes in various environments," Journal of Luminescence, vol. 128, no. 3, pp. 481-488, 2008.

[75] A. Fratini and S. Swavey, "Structural analysis and electronic properties of a homodinuclear erbium(III) complex bridged by the polyazine ligand 2,2'-bipyrimidine," Inorganic Chemistry Communications, vol. 12, no. 6, pp. 509-510, 2009.

[76] M. H. Baker, J. D. Dorweiler, A. N. Ley, R. D. Pike, and S. M. Berry, "Structure and emission spectra of dinuclear lanthanide(III) $\beta$-diketonate complexes with a bridging $2,2^{\prime}$ bipyrimidine ligand," Polyhedron, vol. 28, no. 1, pp. 188-194, 2009.

[77] M. Irfanullah and K. Iftikhar, "New dinuclear lanthanide(III) complexes based on 6,6,7,7,8,8,8-heptafluoro-2,2-dimethyl3,5-octanedione and 2,2' -bipyrimidine," Inorganic Chemistry Communications, vol. 12, no. 4, pp. 296-299, 2009.

[78] M. Irfanullah and K. Iftikhar, "Photoluminescence, optical absorptionand hypersensitivity in mono- and dinuclear lanthanide (TbIII and HoIII) $\beta$-diketonate complexes with diimines and bis-diimine bridging ligand," Journal of Luminescence, vol. 130, no. 11, pp. 1983-1993, 2010.

[79] A. Fratini, G. Richards, E. Larder, and S. Swavey, "Neodymium, gadolinium, and terbium complexes containing hexafluoroacetylacetonate and 2,2'-bipyrimidine: structural and spectroscopic characterization," Inorganic Chemistry, vol. 47, no. 3, pp. 1030-1036, 2008.

[80] A. Fratini and S. Swavey, "Luminescent and structural properties of a $\mathrm{Eu}(\mathrm{III})$ complex: formation of a one-dimensional array bridged by 2,2'-bipyrimidine," Inorganic Chemistry Communications, vol. 10, no. 6, pp. 636-638, 2007.

[81] N. M. Shavaleev, G. Accorsi, D. Virgili et al., "Syntheses and crystal structures of dinuclear complexes containing d-block and f-block luminophores. Sensitization of NIR luminescence from $\mathrm{Yb}(\mathrm{III}), \mathrm{Nd}(\mathrm{III})$, and $\mathrm{Er}(\mathrm{III})$ centers by energy transfer from $\operatorname{Re}(\mathrm{I})$ - and $\mathrm{Pt}(\mathrm{II})$-bipyrimidine metal centers," Inorganic Chemistry, vol. 44, no. 1, pp. 61-72, 2005.

[82] D. J. Berg, J. M. Boncella, and R. A. Andersen, "Preparation of coordination compounds of $\mathrm{Cp} * \mathrm{Yb}$ with heterocyclic nitrogen bases: examples of antiferromagnetic exchange coupling across bridging ligands," Organometallics, vol. 21, no. 22, pp. 4622-4631, 2002.

[83] M. Koziez, R. Pezka, M. Rams, W. Nitek, and B. Sieklucka, "Magnetic properties versus network dimensionality of Cerium(III) Octacyanotungstate(V) compounds," Inorganic Chemistry, vol. 49, no. 9, pp. 4268-4277, 2010.

[84] G. Zucchi, P. Thuéry, E. Rivière, and M. Ephritikhine, "Europium(II) compounds: simple synthesis of a molecular complex in water and coordination polymers with 2,2' bipyrimidine-mediated ferromagnetic interactions," Chemical Communications, vol. 46, no. 48, pp. 9143-9145, 2010.

[85] M. L. Hu, Z. Y. Huang, Y. Q. Cheng et al., "Crystal structure and fluorescence spectrum of the complex [Eu (III) $\left.(\mathrm{TTA})_{3}(\mathrm{phen})\right]$," Chinese Journal of Chemistry, vol. 17, no. 6 , pp. 637-643, 1999.
[86] A. R. Al-Karaghouli and J. S. Wood, "The crystal and molecular structure of trinitratobis(bipyridyl)lanthanum(III)," Inorganic Chemistry, vol. 11, no. 10, pp. 2293-2299, 1972.

[87] J. F. Bower, S. A. Cotton, J. Fawcett, and D. R. Russell, "Bis(2,2' -bipyridyl-N, $\left.N^{\prime}\right)$ tris-(nitrato-O, $\left.O^{\prime}\right)$ neodymium," Acta Crystallographica. Section C, vol. 56, no. 1, pp. e8-e9, 2000.

[88] G. Zucchi, T. Jeon, D. Tondelier et al., "White electroluminescence of lanthanide complexes resulting from exciplex formation," Journal of Materials Chemistry, vol. 20, no. 11, pp. 2114-2120, 2010.

[89] G. A. Brewer and E. Sinn, "Reexamination of a cytochrome oxidase model. A noncoupled iron-copper binuclear complex," Inorganic Chemistry, vol. 23, no. 16, pp. 2532-2537, 1984.

[90] Y. Rodríguez-Martín, J. Sanchiz, C. Ruiz-Pérez, F. Lloret, and M. Julve, "Synthesis, crystal structure and magnetic properties of $\left[\mathrm{Cu}(\mathrm{bpym})(\mathrm{mal})\left(\mathrm{H}_{2} \mathrm{O}\right)\right] \cdot 6 \mathrm{H}_{2} \mathrm{O}$ and $\left[\mathrm{Cu}(\right.$ bpym $\left.)(\mathrm{mal})\left(\mathrm{H}_{2} \mathrm{O}\right)\right] \cdot 4 \mathrm{HO}$ (bpym $=2,2^{\prime}$-bipyrimidine, Hmal=malonic acid)," Inorganica Chimica Acta, vol. 326, no. 1, pp. 20-26, 2001.

[91] G. De Munno, W. Ventura, G. Viau, F. Lloret, J. Faus, and M. Julve, "Structural characterization and magnetic properties of the first 2,2'-bipyrimidine-containing iron(III) complexes," Inorganic Chemistry, vol. 37, no. 7, pp. 14581464, 1998.

[92] A. B. Gaspar, V. Ksenofontov, V. Martinez, M. C. Muñoz, J. A. Real, and P. Gütlich, "A novel dinuclear Fe spincrossover complex based on a 2,2'-bipyrimidine bridge ligand: $\left[\mathrm{Fe}\left(\mathrm{CH}_{3} \text { bipy }\right)(\mathrm{NCS})_{2}\right]_{2}$ bpym," European Journal of Inorganic Chemistry, no. 24, pp. 4770-4773, 2004.

[93] R. H. Petty, B. R. Welch, L. J. Wilson, L. A. Bottomley, and K. M. Kadish, "Cytochrome oxidase models. 2. $\mu$-bipyrimidyl mixed-metal complexes as synthetic models for the $\mathrm{Fe} / \mathrm{Cu}$ binuclear active site of cytochrome oxidase," Journal of the American Chemical Society, vol. 102, no. 2, pp. 611-620, 1980.

[94] G. De Munno, T. Poerio, M. Julve, F. Lloret, and G. Viau, "Synthesis, crystal structure and magnetic properties of the cobalt(II) chain $\left[\mathrm{Co}(\right.$ bipym $\left.)\left(\mathrm{H}_{2} \mathrm{O}\right)_{2}\right]\left(\mathrm{NO}_{3}\right)_{2}$ and the dinuclear compounds $\left[\mathrm{Co}_{2}(\text { bipym })_{3}\left(\mathrm{H}_{2} \mathrm{O}\right)_{4}\right]\left(\mathrm{NO}_{3}\right)_{4} \bullet{ }_{2} \mathrm{H}_{2} \mathrm{O}$ and $\left[\mathrm{Co}_{2}(\text { bipym })_{3}\left(\mathrm{H}_{2} \mathrm{O}\right)_{2}\left(\mathrm{SO}_{4}\right)_{2}\right] \bullet 12 \mathrm{H}_{2} \mathrm{O}$," New Journal of Chemistry, vol. 22, no. 3, pp. 299-305, 1998.

[95] D. Armentano, G. De Munno, F. Guerra, J. Faus, F. Lloret, and M. Julve, "2,2'-Bipyrimidine- and 2,3-bis(2pyridyl)pyrazine-containing manganese(II) compounds: structural and magnetic properties," Dalton Transactions, no. 24, pp. 4626-4634, 2003.

[96] O. Fabelo, J. Pasán, F. Lloret, M. Julve, and C. Ruiz-Pérez, "1,2,4,5-Benzenetetracarboxylate- and 2,2'-bipyrimidinecontaining cobalt(II) coordination polymers: preparation, crystal structure, and magnetic properties," Inorganic Chemistry, vol. 47, no. 9, pp. 3568-3576, 2008.

[97] E. Colacio, J. M. Dominguez-Vera, F. Lloret et al., "Hydrothermal syntheses, crystal structures, and properties of two-dimensional homo- and heterometallic cyanide-bridged complexes: $\left[\mathrm{Cu}_{2}(\mathrm{CN})_{2}(\right.$ bpym $\left.)\right]$ and $\left[\mathrm{Fe}(\text { bipy })_{2}(\mathrm{CN})_{4} \mathrm{Cu}_{2}\right]$ (bpym $=2,2$ '-bipyrimidine, bipy $=2,2^{\prime}$-bipyridine)," Inorganic Chemistry, vol. 42, no. 13, pp. 4209-4214, 2003.

[98] E. Colacio, F. Lloret, M. Navarrete, A. Romerosa, H. Stoeckli-Evans, and J. Suarez-Varela, "2D and 3D coordination polymers based on 2,2'-bipyrimidine and cyanide bridging ligands incorporating coordinated and guest ammonia 
molecules. Synthesis, crystal structures, magnetic properties and thermal analysis of $\left[\mathrm{Ni}(\mathrm{CN})_{4}\right]_{2}\left[\left(\mathrm{Ni}\left(\mathrm{NH}_{3}\right)_{2}\right)_{2}\right.$ (bpym) $]$. $2 \mathrm{H}_{2} \mathrm{On}$ and $\left[\mathrm{Cu}_{2}(\mathrm{CN})_{2}(\mathrm{bpym})\right] \cdot \mathrm{NH}_{3} \mathrm{n}$," New Journal of Chemistry, vol. 29, no. 9, pp. 1189-1194, 2005.

[99] B.-Q. Ma, S. Gao, G. Su, and G.-X. Xu, "Cyano-bridged 4dIf coordination polymers with a unique two-dimensional topological architecture and unusual magnetic behavior," Angewandte Chemie, vol. 40, no. 2, pp. 434-437, 2001.

[100] D. Visinescu, L. M. Toma, O. Fabelo, C. Ruiz-Pérez, F. Lloret, and M. Julve, "New $3 d-4 f$ supramolecular systems constructed by $\left[\mathrm{Fe}(\text { bipy })(\mathrm{CN})_{4}\right]^{-}$and partially blocked lanthanide cations," Polyhedron, vol. 28, no. 4, pp. 851-859, 2009.

[101] J.-M. Herrera, S. G. Baca, H. Adams, and M. D. Ward, "Syntheses and structures of two- and three-dimensional cyanidebridged coordination networks derived from crystallization of diimine- tetracyanoruthenate anions with gadolinium(III) cations," Polyhedron, vol. 25, no. 4, pp. 869-875, 2006.

[102] H. Adams, W. Z. Alsindi, G. M. Davies et al., "New members of the $\left[\mathrm{Ru}(\text { diimine })(\mathrm{CN})_{4}\right]^{2-}$ family: structural, electrochemical and photophysical properties," Dalton Transactions, no. 1, pp. 39-50, 2006. 


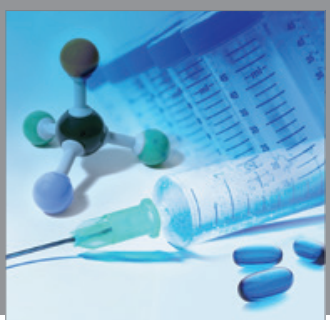

International Journal of

Medicinal Chemistry

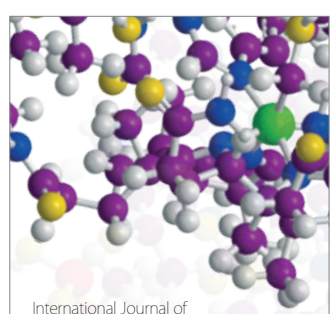

Carbohydrate Chemistry

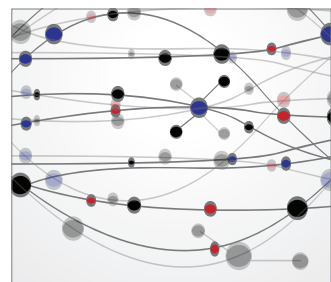

The Scientific World Journal
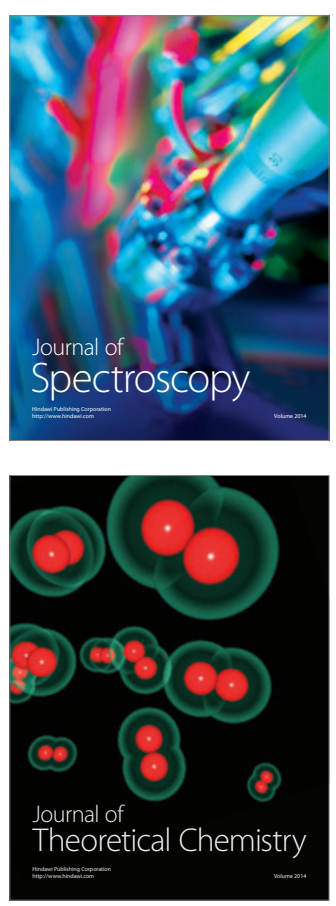
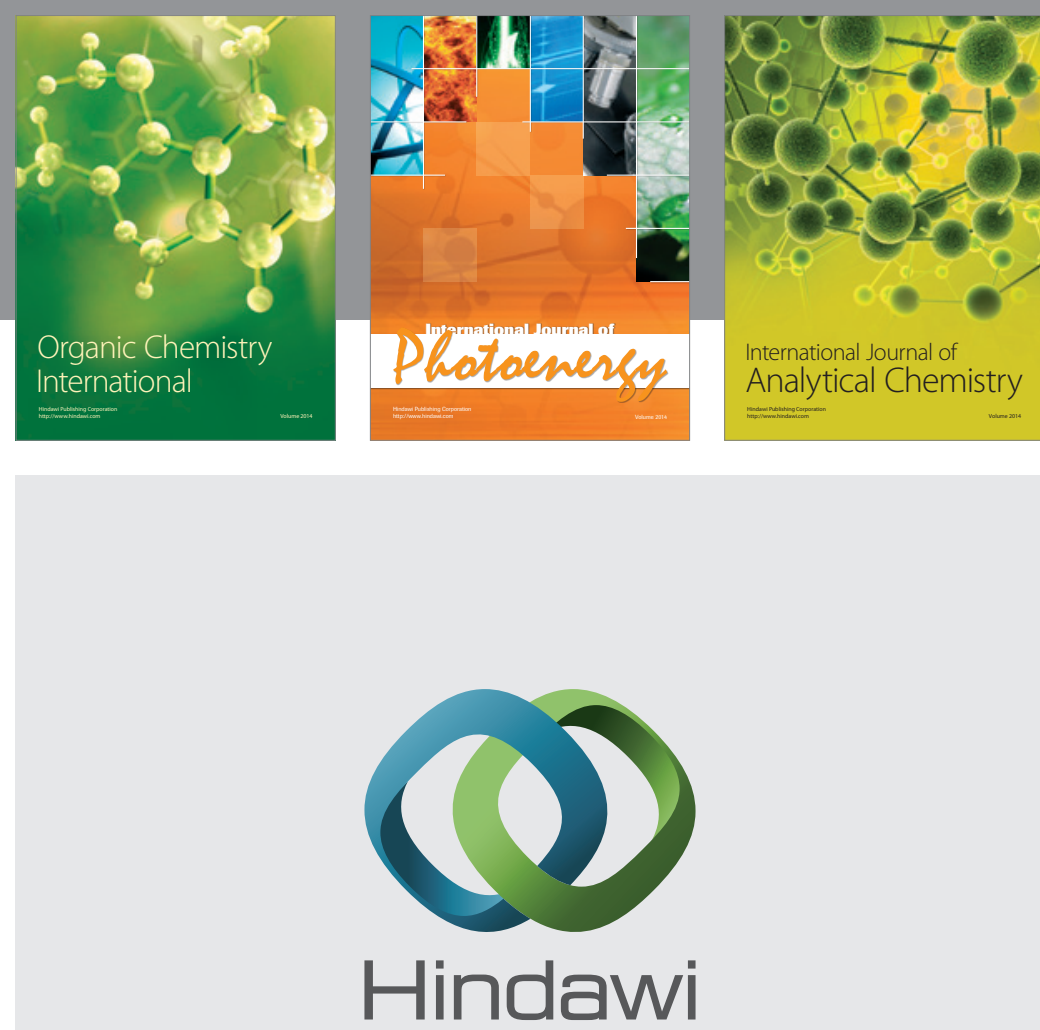

Submit your manuscripts at

http://www.hindawi.com
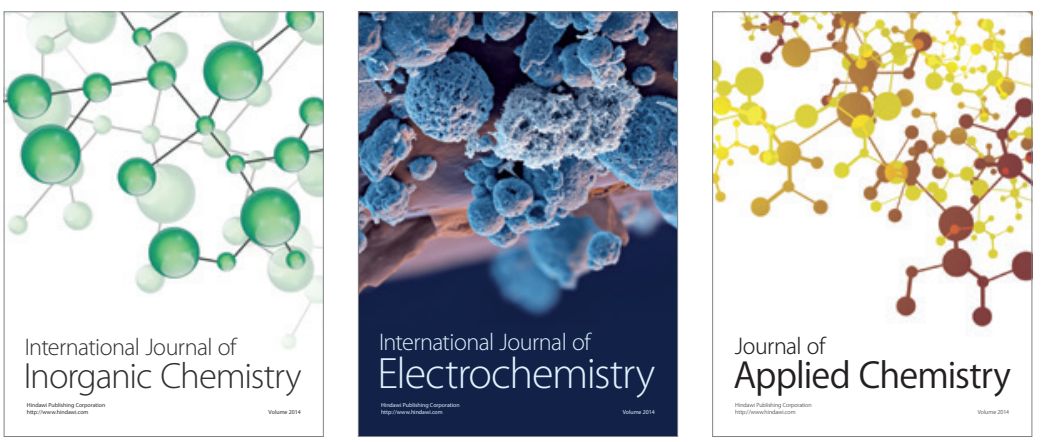

Journal of

Applied Chemistry
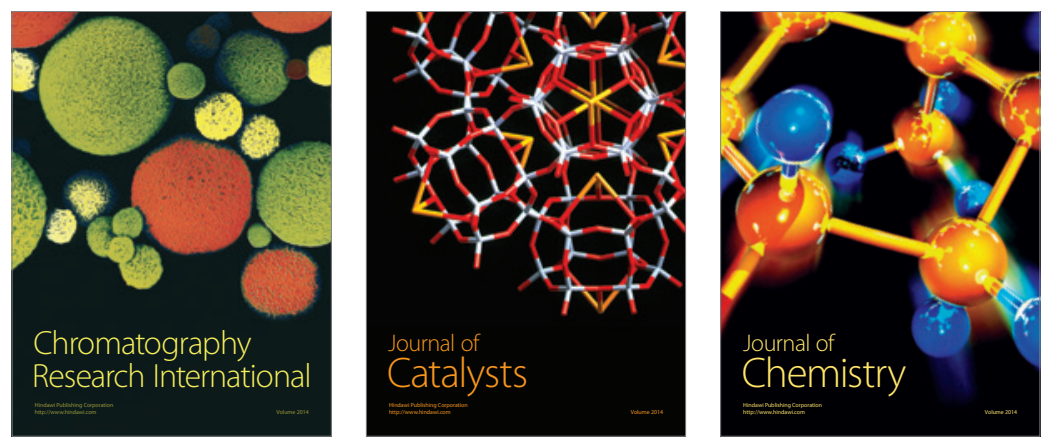
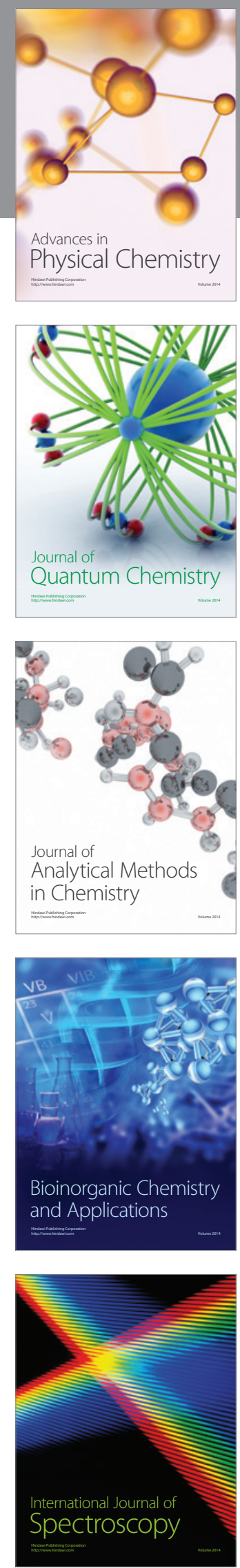